\title{
Neuropeptide $Y$ receptors activation protects rat retinal neural cells against necrotic and apoptotic cell death induced by glutamate
}

\author{
A Santos-Carvalho ${ }^{1,2}$, F Elvas $^{2,3,4}$, AR Álvaro ${ }^{5}$, AF Ambrósio ${ }^{1,3,4}$ and C Cavadas ${ }^{\star, 1,2}$
}

It has been claimed that glutamate excitotoxicity might have a role in the pathogenesis of several retinal degenerative diseases, including glaucoma and diabetic retinopathy. Neuropeptide Y (NPY) has neuroprotective properties against excitotoxicity in the hippocampus, through the activation of $Y_{1}, Y_{2}$ and/or $Y_{5}$ receptors. The principal objective of this study is to investigate the potential protective role of NPY against glutamate-induced toxicity in rat retinal cells (in vitro and in an animal model), unraveling the NPY receptors and intracellular mechanisms involved. Rat retinal neural cell cultures were prepared from newborn Wistar rats (P3-P5) and exposed to glutamate $(500 \mu \mathrm{M})$ for $24 \mathrm{~h}$. Necrotic cell death was evaluated by propidium iodide (PI) assay and apoptotic cell death using TUNEL and caspase-3 assays. The cell types present in culture were identified by immunocytochemistry. The involvement of NPY receptors was assessed using selective agonists and antagonists. Pre-treatment of cells with NPY (100 nM) inhibited both necrotic cell death (PI-positive cells) and apoptotic cell death (TUNEL-positive cells and caspase 3-positive cells) triggered by glutamate, with the neurons being the cells most strongly affected. The activation of NPY $Y_{2}, Y_{4}$ and $Y_{5}$ receptors inhibited necrotic cell death, while apoptotic cell death was only prevented by the activation of NPY $Y_{5}$ receptor. Moreover, NPY neuroprotective effect was mediated by the activation of PKA and p38K. In the animal model, NPY $(2.35 \mathrm{nmol})$ was intravitreally injected $2 \mathrm{~h}$ before glutamate $(500 \mathrm{nmol})$ injection into the vitreous. The protective role of NPY was assessed $24 \mathrm{~h}$ after glutamate (or saline) injection by TUNEL assay and Brn3a (marker of ganglion cells) immunohistochemistry. NPY inhibited the increase in the number of TUNEL-positive cells and the decrease in the number of Brn3a-positive cells induced by glutamate. In conclusion, NPY and NPY receptors can be considered potential targets to treat retinal degenerative diseases, such as glaucoma and diabetic retinopathy.

Cell Death and Disease (2013) 4, e636; doi:10.1038/cddis.2013.160; published online 16 May 2013

Subject Category: Neuroscience

Neuropeptide Y (NPY) is one of the most abundant peptides in the mammalian central nervous system (CNS). ${ }^{1-3}$ NPY is a highly conserved peptide containing 36 amino acids. Its biological effects are mediated by six G-protein-coupled receptors $Y_{1}, Y_{2}, Y_{3}, Y_{4}, Y_{5}$ and $y_{6} \cdot{ }^{3-5}$ The retina is a specialized nervous tissue where NPY and its receptors are expressed in the retina of different species. ${ }^{6,7}$ The presence of mRNA for $Y_{1}, Y_{2}, Y_{4}$ and $Y_{5}$ NPY receptors has been detected in rat retinas ${ }^{8,9}$ and in cultured rat retinal neural cells, ${ }^{8}$ but their distribution in different cell types and their function in the retina is poorly understood.

Glutamate is the main excitatory neurotransmitter in the CNS, including in retina. ${ }^{10}$ Excitotoxicity, which is considered as an overactivation of glutamate receptors triggering neuronal cell death, has been associated with several acute and chronic neurodegenerative disorders ${ }^{11,12}$ and in retinal degenerative disorders, such as glaucoma ${ }^{13-15}$ and diabetic retinopathy. ${ }^{16-18}$

NPY has been linked to several physiological and pathological functions, such as feeding behaviour, memory processing, pain, anxiety, cell proliferation and many other processes in the central and peripheral nervous systems. ${ }^{19,20}$ Some studies have demonstrated putative neuroprotective effects of NPY in various regions of the CNS. In particular, NPY inhibits the glutamate release in rat hippocampus and is neuroprotective in rat hippocampus and striatum. ${ }^{2,21-25}$ Moreover, the activation of NPY $Y_{1}, Y_{2}$ and $Y_{5}$ receptors mediates the neuroprotective effect of NPY against AMPA- and kainate-induced excitotoxicity in organotypic rat hippocampal slice cultures. ${ }^{21}$ It has also been suggested that selective activation of $Y_{1}$ and $Y_{2}$ receptors protects mouse hippocampal cells from excitotoxic lesions. ${ }^{24}$ Similarly, NPY

\footnotetext{
${ }^{1} \mathrm{CNC}$ - Center for Neuroscience and Cell Biology, University of Coimbra; Largo Marquês de Pombal, Coimbra, Portugal; ${ }^{2}$ Faculty of Pharmacy, University of Coimbra, Pólo das Ciências da Saúde, Azinhaga de Santa Comba, Coimbra, Portugal; ${ }^{3}$ Centre of Ophthalmology and Visual Sciences, IBILI, Faculty of Medicine, University of Coimbra, Pólo das Ciências da Saúde, Azinhaga de Santa Comba, Coimbra, Portugal; ${ }^{4}$ AIBILI - Association for Innovation and Biomedical Research on Light and Image, Azinhaga de Santa Comba, Coimbra, Portugal and ${ }^{5}$ Department of Biology and Environment; University of Trás-os-Montes and Alto Douro, Vila Real, Portugal *Corresponding author: C Cavadas, Faculty of Pharmacy, University of Coimbra, Pólo das Ciências da Saúde, Azinhaga de Santa Comba, Coimbra 3000-548, Portugal. Tel: +351 239859950; Fax: +351 239827126; E-mail: ccavadas@uc.pt

Keywords: Retinal cells; neuropeptide Y; NPY receptors; neuroprotection; glutamate

Abbreviations: GCL, ganglion cell layer; GFAP glial fibrillary acidic protein; INL, inner nuclear layer; L-NAME, L-NG-nitroarginine methyl ester; CNS, central nervous system; MDMA, 3,4-methylenedioxy-N-methylamphetamine; NOS, nitric oxide synthase; NPY, neuropeptide Y; ONL, outer nuclear layer; PI, propidium iodide; RT, room temperature; BSA, bovine serum albumin; PBS, phosphate-buffered saline; PFA, paraformaldehyde; PI3K, phosphatidylinositol 3-kinase; PKA, protein kinase A; PKC, protein kinase C; TUNEL, terminal deoxynucleotidyl transferase (TdT) dUTP nick end labeling

Received 03.12.12; revised 27.3.13; accepted 08.4.13; Edited by A Verkhratsky
} 
$Y_{2}$ and $Y_{5}$ are implicated in the neuroprotective role against kainate-induced excitotoxicity in hippocampus even after delayed application of the respective agonists. Specific activation of NPY $Y_{2}$ receptor is also effective in a transient middle cerebral artery occlusion model of ischemia. ${ }^{23}$ Recently, it was shown that NPY, also through NPY $Y_{2}$ receptor activation, mediates the survival of dopaminergic neurons in Parkinson's disease models. ${ }^{26}$ In addition, NPY
A

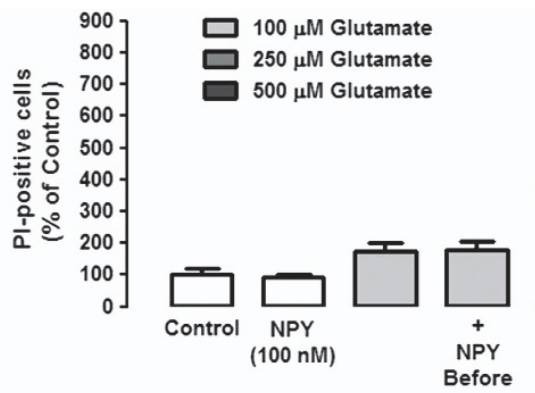

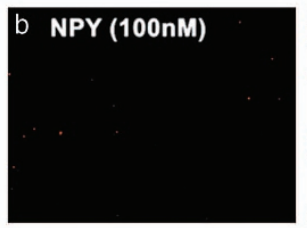

C 흐
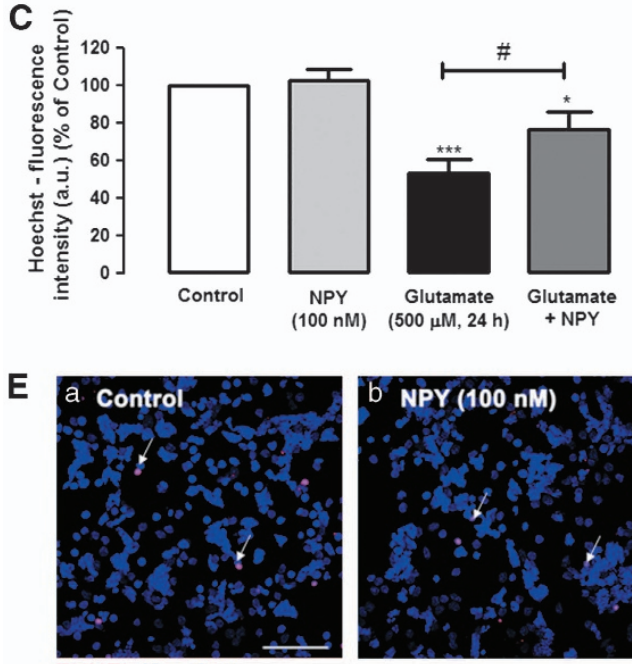

TUNEL Hoochet
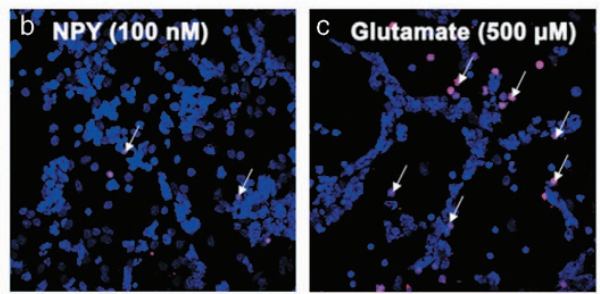

D
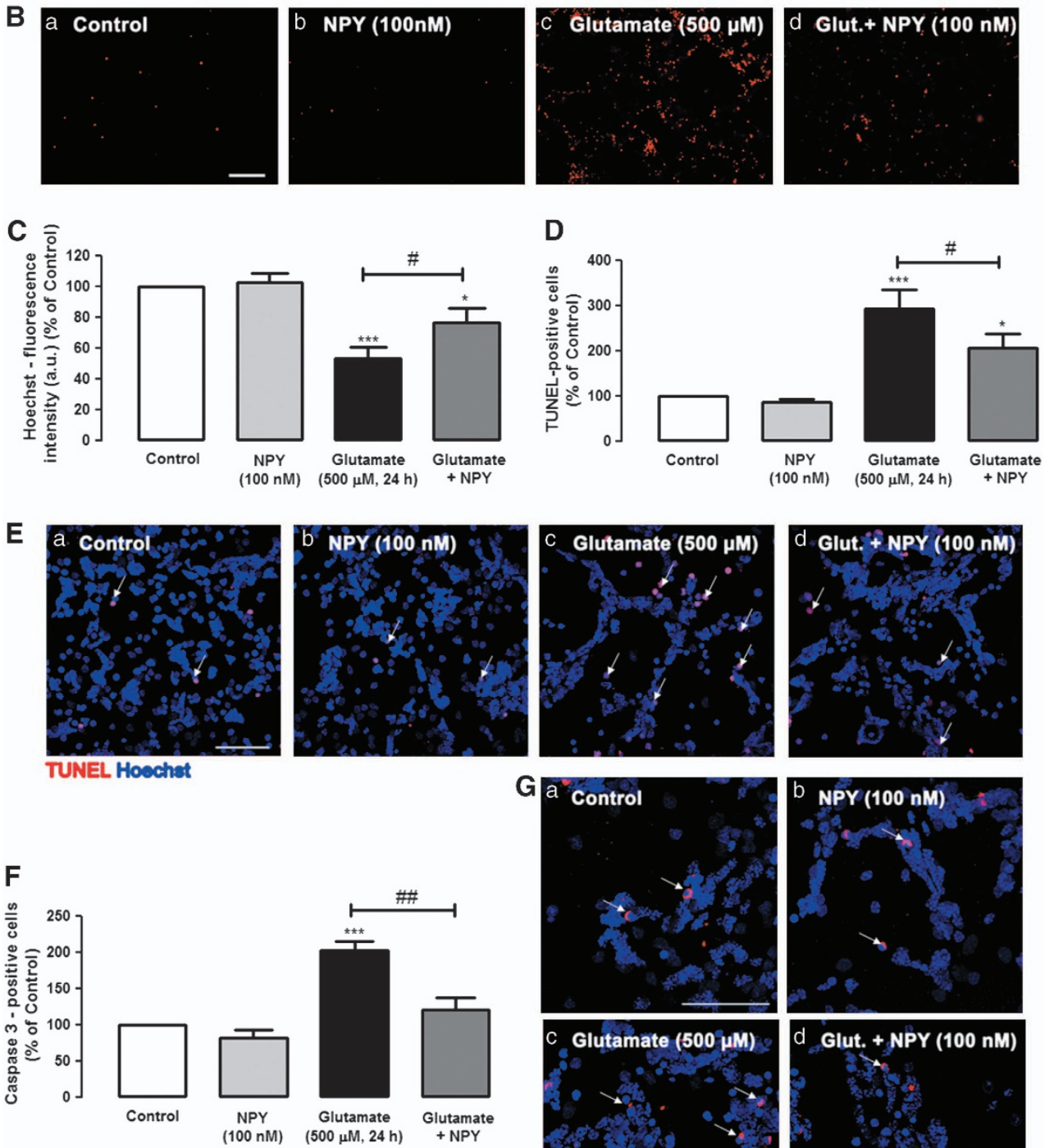

Caspase 3 Hoechst
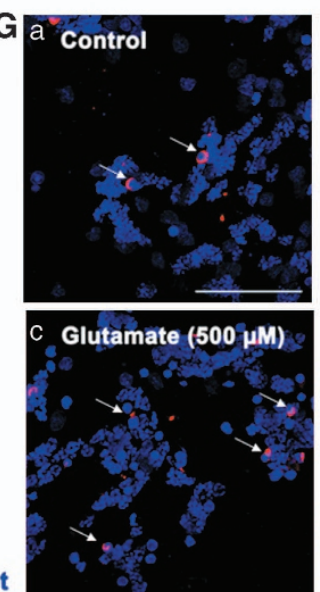
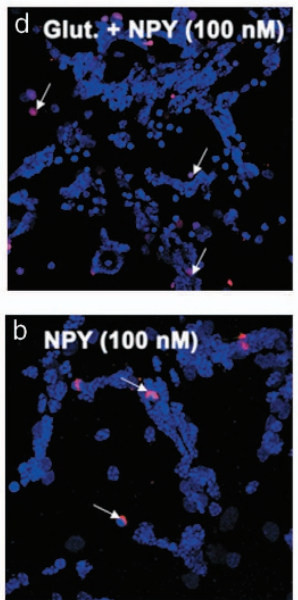

d Glut. + NPY (100 nM)

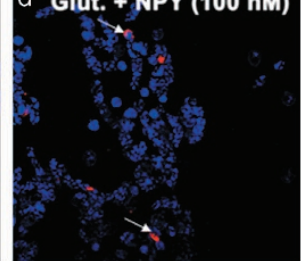


was suggested as a potential neuroprotective agent in Alzheimer's disease by counteracting the toxic effect of $\beta$-amyloid in an in vitro model. ${ }^{27,28}$

We have also shown that NPY in the retina presents neuroprotective properties. Specifically, NPY protected rat retinal cells in culture against 3,4-methylenedioxy-N-methylamphetamine (MDMA)-induced toxicity, ${ }^{29}$ although the NPY receptor subtype(s) involved in this neuroprotective effect is unknown.

As the retina is affected by various degenerative diseases, where glutamate excitotoxicity might eventually have a role, ${ }^{13,17}$ our major goal in the present work is to evaluate the putative neuroprotective role of NPY and NPY receptors against glutamate excitotoxicity in retinal cells. We have evaluated the involvement of the different NPY receptors, as well as the possible intracellular signaling pathways involved in the neuroprotective effects of NPY in retinal cells, using primary rat retinal neural cell cultures.

\section{Results}

NPY protects neurons against necrotic and apoptotic cell death induced by glutamate. Necrotic and late apoptotic cell death of rat retinal neural cells was evaluated by propidium iodide $(\mathrm{Pl})$ uptake assay. Retinal cells were exposed to 100,250 or $500 \mu \mathrm{M}$ glutamate for $24 \mathrm{~h}$ (Figures $1 \mathrm{~A}$ and $\mathrm{B}$ ). The number of $\mathrm{PI}$-positive cells in coverslips exposed to 100,250 or $500 \mu \mathrm{M}$ of glutamate was $175.7 \pm 27.1 \%$, $364.7 \pm 64.4 \%$ and $617.3 \pm 71.7 \%$ of control, respectively. These results indicate that cell viability decreases significantly with increased glutamate concentrations. To investigate the potential neuroprotective role of NPY against glutamateinduced toxicity, retinal cells were incubated with NPY $(100 \mathrm{nM})$ at three different times: $1 \mathrm{~h}$ before the incubation with glutamate $(100,250$ and $500 \mu \mathrm{M})$, simultaneously with the addition of glutamate $(500 \mu \mathrm{M})$ and 30 min after exposure to glutamate $(500 \mu \mathrm{M})$. NPY did not affect the increase in the number of PI-positive cells induced by exposure to $100 \mu \mathrm{M}$ glutamate, as the number of PI-positive cells $(179.9 \pm 25.0 \%$ of control-NPY applied $1 \mathrm{~h}$ before glutamate) was similar to glutamate alone. When cells were exposed to $250 \mu \mathrm{M}$ glutamate, there was a tendency, although not significant, for a protective effect of NPY when applied before glutamate. A neuroprotective effect of NPY was observed when $500 \mu \mathrm{M}$ glutamate stimulus was applied. When cells were exposed to $500 \mu \mathrm{M}$ glutamate, and NPY $(100 \mathrm{nM})$ was added $1 \mathrm{~h}$ before glutamate, there was a significant neuroprotective effect of NPY, as shown by a decrease in the number of PI-positive cells to $409.4 \pm 41.8 \%$ of control (Figures $1 \mathrm{~A}$ and $\mathrm{Bd}$ ), which can be compared with the glutamate condition $(617.3 \pm 71.7 \%$ of control), indicating a decrease in the number of PI-positive cells of $34 \%$. However, when cells were exposed to NPY, either simultaneously or $30 \mathrm{~min}$ after adding $500 \mu \mathrm{M}$ glutamate, the neuroprotective effect was lost. Under the two conditions, the number of PI-positive cells was $614.7 \pm 80.5 \%$ and $756.9 \pm 78.0 \%$ of control, respectively, similar to percentage found when cells were exposed to $500 \mu \mathrm{M}$ glutamate $(617.3 \pm 71.7 \%$ of control). Based on these results, NPY was applied $1 \mathrm{~h}$ before glutamate $(500 \mu \mathrm{M})$ for the subsequent experiments.

The effects of glutamate and/or NPY treatments on the total number of cells were also assessed (Figure 1C). Cells were stained with Hoechst33342, and the fluorescence intensity (arbitrary units) was measured. Glutamate (500 $\mu \mathrm{M}, 24 \mathrm{~h})$ was found to decrease the Hoechst33342-fluorescence intensity to $50.8 \pm 7.0 \%$ of control (untreated cells). NPY partially prevented this effect triggered by glutamate, as the decrease in fluorescence intensity was attenuated by NPY $(75.4 \pm 9.8 \%$ of control).

Apoptotic cell death was assessed using the TUNEL (terminal deoxynucleotidyl transferase (TdT) dUTP nick end labeling) assay to obtain a better characterization of the protective role of NPY against retinal cell death caused by exposure to glutamate (Figures $1 \mathrm{D}$ and E). Glutamate $(500 \mu \mathrm{M})$ increased the number of apoptotic cells to $294.1 \pm 41.7 \%$ of control. When NPY (100 nM) was applied $1 \mathrm{~h}$ before glutamate, the increase in the number of TUNELpositive cells triggered by glutamate was reduced to $206.2 \pm 32.6 \%$ of control, representing a $30 \%$ reduction. In addition, although glutamate $(500 \mu \mathrm{M}, 24 \mathrm{~h})$ increased the number of active caspase 3-positive cells to $201.9 \pm 12.8 \%$ of control (Figures 1F and Gc), NPY pre-treatment reduced the increase in the number of caspase 3-positive cells triggered by glutamate to $120.7 \pm 16.7 \%$ of control (Figure $1 \mathrm{Gd}$ ).

Figure 1 NPY protects against necrotic and apoptotic retinal cell death induced by glutamate. (A and $\mathbf{B})$ Necrotic cells were assessed by PI incorporation assay. (C) Cell nuclei were stained by Hoechst 33342. Apoptotic cells were assessed by ( $\mathbf{D}$ and $\mathbf{E})$ TUNEL assay and (F and $\mathbf{G}$ ) cleaved caspase 3- immunocytochemistry. (A) Quantification of PI-positive cells (percentage of control). Retinal cells were exposed to different concentrations of glutamate (100,250 and $500 \mu \mathrm{M})$ for $24 \mathrm{~h}$ and treated with NPY (100 nM) at three different time points: $1 \mathrm{~h}$ before, simultaneously, and $30 \mathrm{~min}$ after glutamate, as indicated below bars. The results represent the mean \pm S.E.M of $n=4-11$ independent experiments; ${ }^{* *} P<0.001,{ }^{* *} P<0.01,{ }^{*} P<0.05$, compared with control; ${ }^{\#} P<0.05$, compared with glutamate $(500 \mu \mathrm{M})$; one-way analysis of variance (ANOVA) followed by Bonferroni's post-hoc test. (B) Representative images of (a) control and cultures treated with (b) NPY, (c) glutamate or (d) glutamate + NPY (1 h before), showing Pl-positive cells (red spots), Bar $=100 \mu \mathrm{m}$. (C) Quantification of fluorescence intensity (arbitrary units) of cells stained with Hoechst 33342 (nucleus marker), compared with control (no drug). These results represent the mean \pm S.E.M. of $n=21-27$ independent experiments; ${ }^{* * *} P<0.001,{ }^{*} P<0.05$, compared with control; ${ }^{\#} P<0.05$, compared with glutamate; one-way ANOVA followed by Bonferroni's post-hoc test. (D) Quantification of TUNEL-positive cells (percentage of control). Cultured retinal cells were exposed to glutamate and treated with NPY ( $1 \mathrm{~h}$ before glutamate exposure), as indicated below bars. Data represent the mean \pm S.E.M. of $n=5-6$ independent experiments; ${ }_{* \star *} P<0.001,{ }^{*} P<0.05$, compared with control; ${ }^{\#} P<0.05$, compared with glutamate; one-way ANOVA followed by Bonferroni's post-hoc test. (E) Representative images of (a) control and cultures treated with (b) NPY, (c) glutamate or (d) glutamate + NPY (1 h before), showing TUNEL-positive cells (purple spots, indicated by white arrows) and cell nuclei stained with Hoechst 33342 (blue); Bar $=50 \mu \mathrm{m}$. (F) Quantification of cleaved caspase-3 positive cells (red) per field compared with control conditions (100\%; no drug, Ga). Rat retinal cells were exposed to glutamate and treated with NPY (1 $\mathrm{h}$ before glutamate exposure), as indicated below bars. The results represent the mean \pm S.E.M. of $n=5-6$ independent experiments; ${ }^{* \star *} P<0.001,{ }^{*} P<0.05$, compared with control; ${ }^{\#} P<0.05$, compared with glutamate; one-way ANOVA followed by Bonferroni's post-hoc test. (G) Representative images of (a) control and cultures treated with (b) NPY, (c) glutamate or (d) glutamate + NPY ( $1 \mathrm{~h}$ before), showing cleaved caspase 3-positive cells (purple spots). Cell nuclei were stained with Hoechst 33342 (blue). NPY per se had no effect on the number of PI-, Hoechst $33342-$, TUNEL-, or cleaved caspase 3-positive cells compared with control. Bar $=50 \mu \mathrm{m}$ 
A
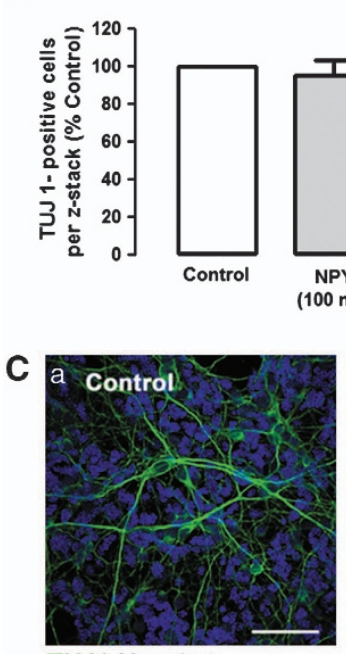

TUJ1 Hoechst
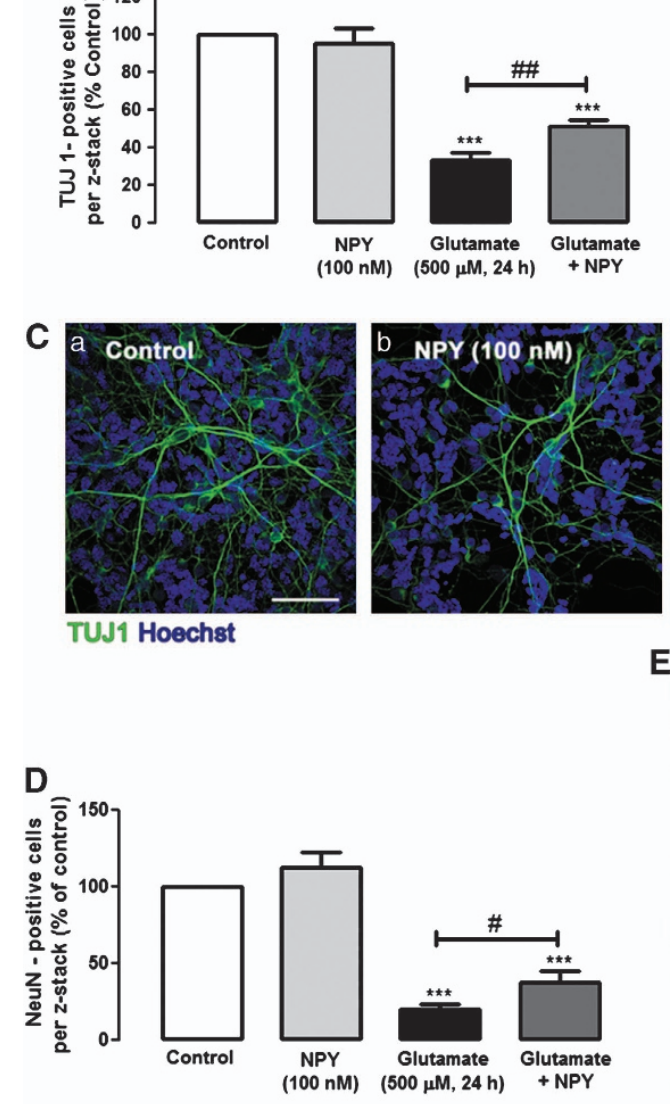

NouN Hoechst
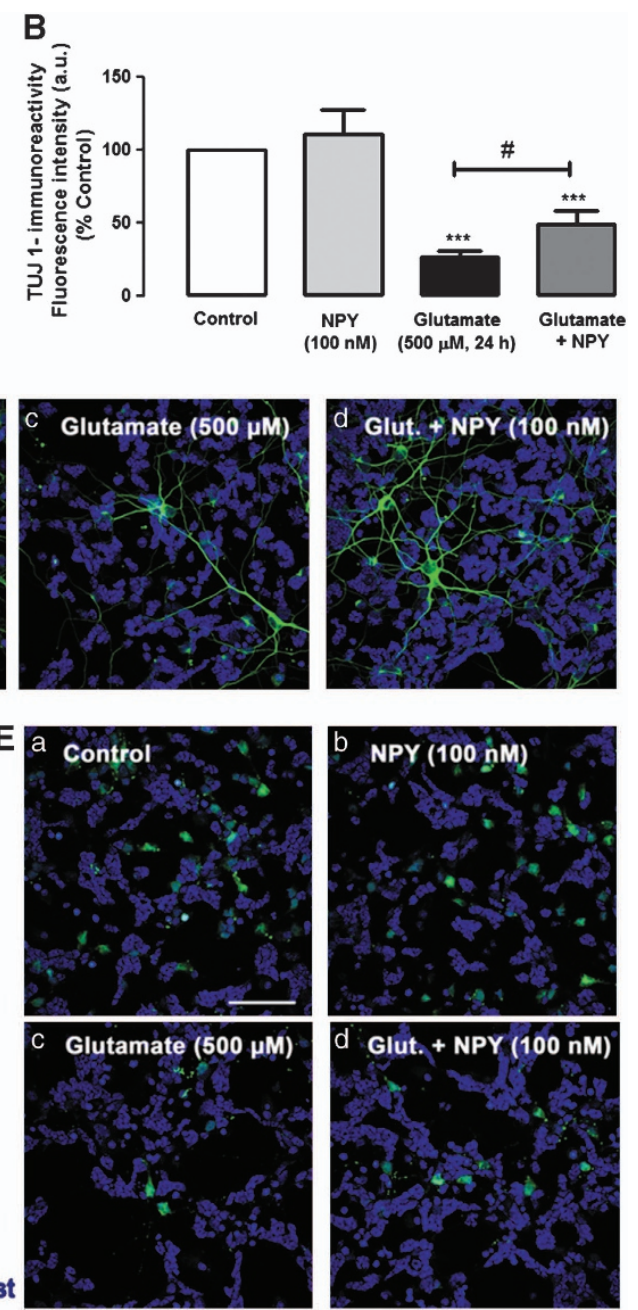

Figure 2 NPY protects neuronal cell death induced by glutamate in rat retinal neural cell cultures. Neurons were identified with (C) anti-TUJ1 (green) or (E) anti-NeuN (green) antibodies, respectively. (A) Quantification of TUJ1-positive cells per z-stack. The results were normalized and are presented as percentage of control condition. The results represent the mean \pm S.E.M. of $n=5-7$ independent experiments; ${ }^{* * *} P<0.001$, compared with control; ${ }^{\# \#} P<0.01$, compared with glutamate; one-way analysis of variance (ANOVA) followed by Bonferroni's post-hoc test. (B) Quantification of TUJ 1-immunoreactivity by fluorescence intensity (arbitrary units), compared with control conditions (100\%; no drug, Ca). The results represent the mean \pm S.E.M. of $n=4-8$ independent experiments ${ }^{\star \star \star} P<0.001$, compared with control; ${ }^{*} P<0.05$, compared with glutamate; one-way ANOVA followed by Bonferroni's post-hoc test. (C) Representative images of (a) control cultures and cultures treated with (b) NPY, (c) glutamate or (d) glutamate + NPY, showing TUJ1-positive cells (green). Cell nuclei were identified by Hoechst 33342 staining (blue). (D) Quantification of NeuN-positive cells per z-stack. The

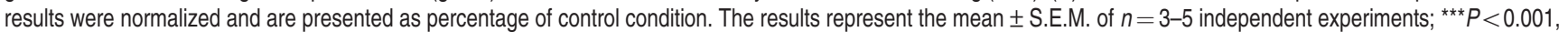
compared with control; ${ }^{*} P<0.05$, compared with glutamate; one-way ANOVA followed by Bonferroni's post-hoc test. (E) Representative images of (a) control cultures and cultures treated with (b) NPY, (c) glutamate or (d) glutamate + NPY, showing NeuN-positive cells (green). Cell nuclei were stained with Hoechst 33342 (blue). NPY per se did not affect the number of TUJ1- or NeuN-positive cells or the TUJ1-immunoreactivity compared with control. Bar $=50 \mu \mathrm{m}$

To further elucidate the protective effect of NPY against glutamate-induced cell death and considering that these cell cultures are composed of neurons, macroglial and microglial cells, we evaluated, by immunocytochemistry, which cell types could be most strongly affected by glutamate and, eventually, protected by NPY (Figures 2-4). To quantify the effects of glutamate and NPY on different cell types, the immunoreactivity (fluorescence intensity) and/or the number of positive cells to different cell markers were evaluated. Under control conditions, a normal distribution of TUJ1-positive neurons was observed (Figures 2Ca). When cells were exposed to $500 \mu \mathrm{M}$ glutamate for $24 \mathrm{~h}$, the number of neurons decreased and their neurites integrity was dramatically affected (Figure 2Cc). The quantification of
TUJ1-positive cells (Figure 2A) revealed that glutamate induced a significant decrease in the number of neurons in culture to $33.4 \pm 3.8 \%$ of control. The application of NPY before glutamate inhibited significantly the decrease in the number of TUJ1-positive cells to $51.4 \pm 3.6 \%$ of control. Additionally, by analyzing the TUJ-1-immunoreactivity (Figure 2B), we also found that glutamate induced a significant decrease in the content of this neuronal marker to $26.0 \pm 4.9 \%$ of control (Figure 2B). In cells incubated with NPY before glutamate application, the decrease in TUJ-1 immunoreactivity was attenuated $(49.2 \pm 8.5 \%$ of control), compared with cells just exposed to glutamate. In rat retinal cell cultures, among several neuronal markers, TUJ1 presents the best immunoreactivity profile. However, TUJ1 is considered an 
A
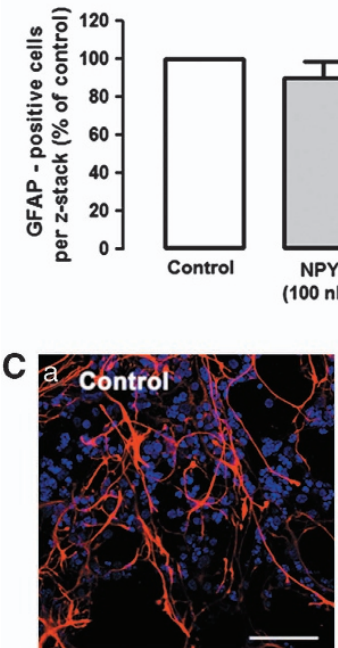

GFAP Hoechet
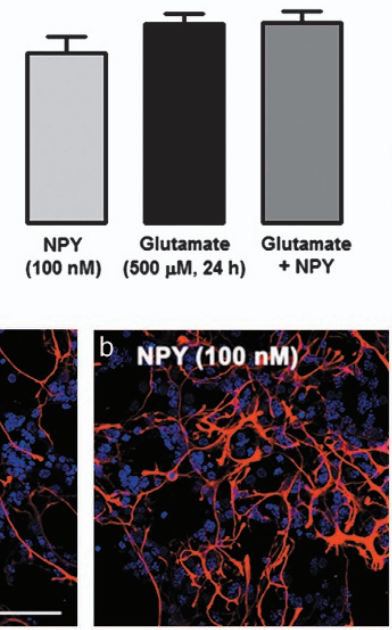

B
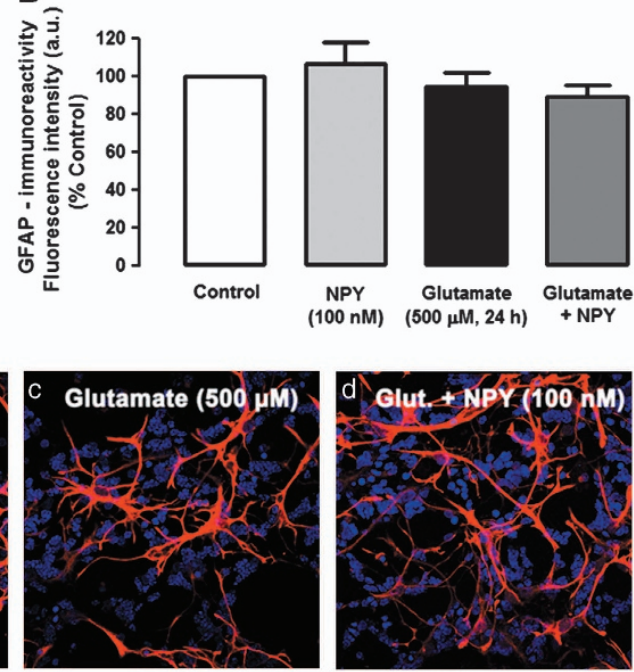

Figure 3 NPY has no effect in glial cells. Microglial cells were identified with (C) anti-GFAP (red) antibody. (A) Quantification of GFAP-positive cells per z-stack. (B) Quantification of GFAP-immunoreactivity by fluorescence intensity (arbitrary units), compared with control conditions (100\%; no drug, Ca). The results were normalized and are presented as percentage of control condition. (C) Representative images of (a) control and cultures treated with (b) NPY, (c) glutamate or (d) glutamate + NPY, showing GFAP-positive cells (red). Cell nuclei were stained with Hoechst 33342 (blue). NPY per se did not affect the number of GFAP-positive cells or the GFAPimmunoreactivity compared with control. Bar $=50 \mu \mathrm{m}$

immature neuronal marker, and therefore the expression of NeuN, a marker of mature neurons, was also evaluated in the same conditions. Similar results were found (Figures 2D and E). The number of NeuN-positive cells dramatically decreased in the presence of $500 \mu \mathrm{M}$ glutamate to $19.8 \pm 4.0 \%$ of control. The pre-incubation of the retinal cells with NPY inhibited the decrease in the number of NeuN-positive cells triggered by glutamate (38.1 $\pm 7.2 \%$ of control). To evaluate the effects of glutamate and NPY on macroglial cells, we analyzed the immunoreactivity of glial fibrillary acidic protein (GFAP), a macroglial cell (astrocytes and Müller cells) marker (Figure 3). The number of GFAP-positive cells (Figure 3A) and the GFAP immunoreactivity (fluorescence intensity) were evaluated (Figure 3B). We found that exposure of retinal cells to glutamate induced a slight change in the morphology of some GFAP-positive cells, compared with control cells (Figure $3 \mathrm{Bc}$ ), namely a decrease in the number of cell processes and an increase of their thickness (Figure 3Bc). However, by evaluating the number of GFAP-positive cells and the quantification of GFAP immunoreactivity (fluorescence intensity) revealed no significant differences between cells exposed to glutamate and controls. These small alterations in GFAP-positive cell morphology triggered by glutamate appeared to be partially prevented by NPY (Figure 3Bd). The effects of glutamate and NPY on microglial cells were assessed by analyzing the immunoreactivity of two microglial cell markers: CD11b and CD68/ED1 (Figure 4). CD11b labels resting and activated microglial cells, while ED1 is a marker of activated microglia. ${ }^{30}$ Two different parameters were evaluated for these markers: the number of CD11b- and CD68/ ED1-positive cells per field, and the CD11b or CD68/ED1 immunoreactivity. NPY increased the number of microglial cells (resting and activated; Figures $4 \mathrm{Cb}$ and $\mathrm{Fb}$ ). Similarly, glutamate or NPY plus glutamate also increased the number of CD11b- and CD68/ED1-positive cells. As with the results obtained for the number of CD11b-positive cells, the fluorescence intensity measurements showed that NPY, glutamate and NPY plus glutamate increased the immunoreactivity of CD11b- and CD68/ED1-positive cells (Figures 4B and $\mathrm{E}$ ).

Activation of NPY $Y_{2}, Y_{4}$ or $Y_{5}$ receptors inhibits the increase in necrotic cell death induced by glutamate. We evaluated the effects of NPY receptor agonists and antagonists to determine which NPY receptors could be mediating the protective role of NPY against necrotic cell death induced by glutamate (Figures $5 \mathrm{~A}$ and $\mathrm{B}$ ). In this analysis, we compared the number of PI-positive cells for each experimental condition with the number of PI-positive cells in cultures exposed to glutamate, taken as $100 \%$. NPY decreased the number of PI-positive cells to $72.4 \pm 3.7 \%$ relative to glutamate. The NPY $Y_{1}$ receptor agonist ([Leu, ${ }^{31}$ Pro $^{34}$ JNPY) did not inhibit glutamate-induced necrotic cell death (Figures $5 \mathrm{~A}$ and $\mathrm{B}$ ). However, the NPY $\mathrm{Y}_{2}$ receptor agonist (NPY ${ }_{13-36}$ ) inhibited the increase in PI-positive cells $(68.8 \pm 6.4 \%$, compared with glutamate; Figure $5 \mathrm{~A})$. This protective effect was partially prevented by the NPY $\mathrm{Y}_{2}$ receptor antagonist BIIE0246 (83.4 $\pm 7.2 \%$ compared with glutamate). Furthermore, the NPY $\mathrm{Y}_{4}$ agonist (r-PP, $100 \mathrm{nM}$ ) also partially protected retinal cells exposed to glutamate, as shown by the number of $\mathrm{Pl}$-positive cells decreasing to $60.2 \pm 15.5 \%$ relative to glutamate. In addition, NPY $Y_{5}$ receptor agonist (Gly, ${ }^{1}$ Ser, ${ }^{3,22} \mathrm{Gln},{ }^{4,34} \mathrm{Thr},{ }^{6} \mathrm{Arg},{ }^{19} \mathrm{Tyr},{ }^{21}$ Ala, ${ }^{23,31} \mathrm{Aib}^{32}$ )PP also exerted a protective effect, as seen by the increase in the number of PI-positive cells induced by glutamate, which was attenuated to $73.0 \pm 4.4 \%$, compared with glutamate (Figures $5 \mathrm{~A}$ and $\mathrm{B}$ ). This effect was completely blocked by NPY $Y_{5}$ receptor antagonist. The 
A
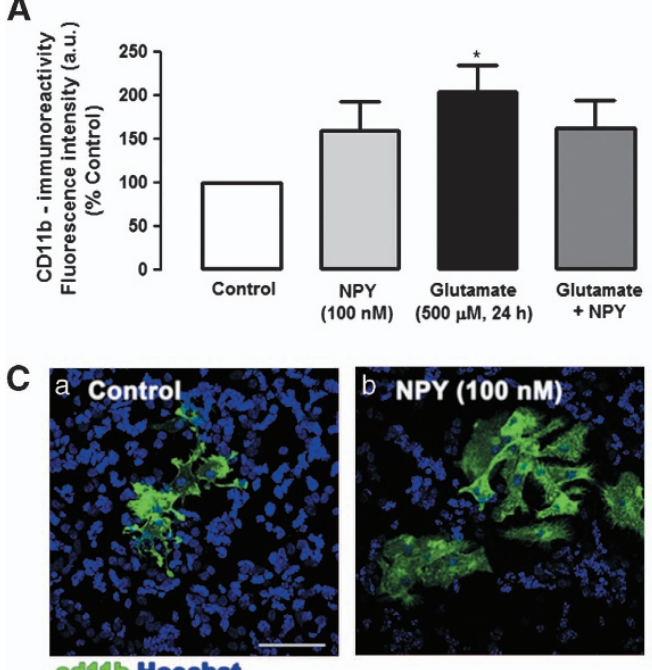

D
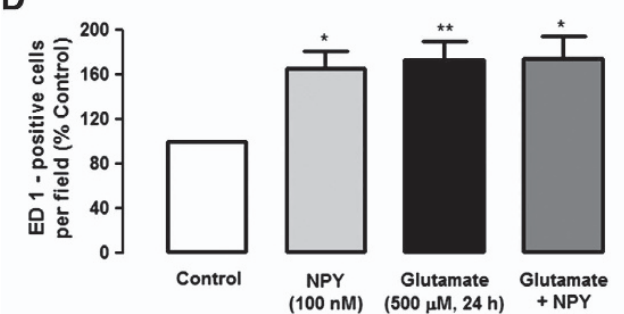

$\mathbf{F}$
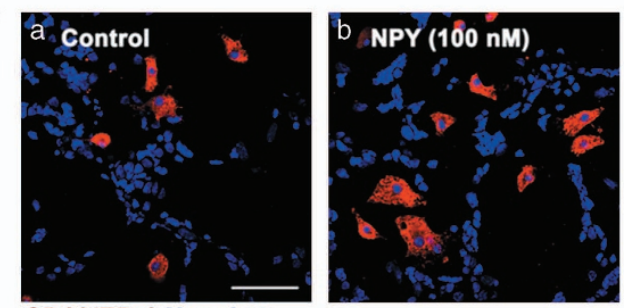

B
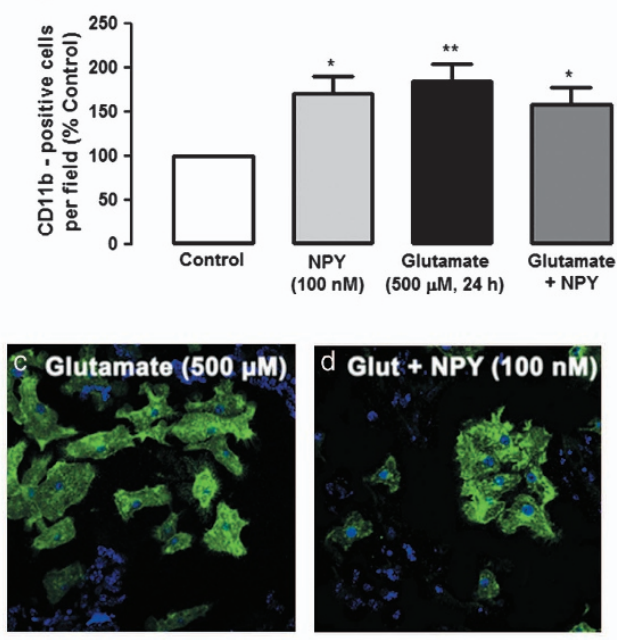

E
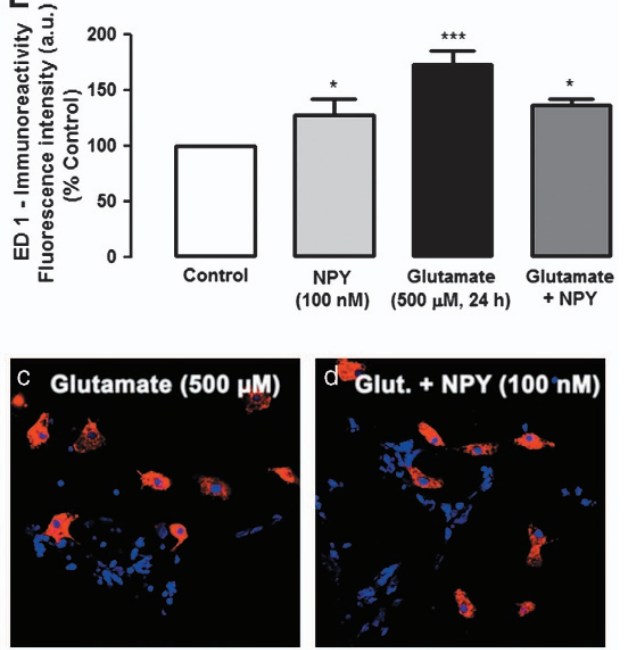

Figure 4 Glutamate and NPY increase the proliferation and activation of retinal microglial cells. Microglial cells were identified by immunocytochemistry using (C) anti-CD11b (green) and (F) anti-CD68/ED1 (red) antibodies. (A) Quantification of CD11b-positive cells (green) per field, compared with control conditions (no drug, Ca). (B) Quantification of fluorescence intensity (arbitrary units) of CD11b-immunoreactivity, compared with control (100\%; no drug, Ca). These results (A and B) represent the mean \pm S.E.M. of $n=8$ independent experiments, with ${ }^{* *} P<0.01,{ }^{*} P<0.05$, compared with control; one-way analysis of variance (ANOVA) followed by Bonferroni's posthoc test. (C) Representative images of (a) control and cultures treated with (b) NPY, (c) glutamate or (d) glutamate + NPY, showing CD11b- positive cells (green). Cell nuclei were stained by Hoechst 33342 (blue). Bar $=50 \mu \mathrm{m}$. (D) Quantification of CD68/ED1-positive cells per field, compared with control (100\%; no drug, Da). (E) Quantification of fluorescence intensity (arbitrary units) of CD68/ED1-immunoreactivity, compared with control (100\%; no drug, Da). These results (D and E) represent the mean \pm S.E.M. of $n=5$ independent experiments; ${ }^{* \star \star} P<0.001$, ${ }^{*} P<0.01,{ }^{*} P<0.05$, compared with control; one-way ANOVA followed by Bonferroni's post-hoc test. (F) Representative images of (a) control, and cultures treated with (b) NPY, (c) glutamate or (d) glutamate + NPY, showing CD 68/ED1-positive cells. Cell nuclei were stained by Hoechst 33342 (blue). Bar $=50 \mu \mathrm{m}$

NPY receptor agonists or antagonists per se did not increase the number of PI-positive cells, compared with control (data not shown).

NPY $Y_{5}$ receptor activation inhibits apoptotic retinal cell death induced by glutamate. We have evaluated the potential neuroprotective effect of NPY receptor agonists against the increase in apoptotic cell (TUNEL-positive cells) number by exposure to glutamate. NPY reduced $30 \%$ the number of apoptotic cells to $69.7 \pm 3.8 \%$, compared with glutamate. NPY receptor agonists and antagonists were used to investigate those involved in this neuroprotective effect (Figures $6 \mathrm{~A}$ and $\mathrm{B}$ ). The NPY $\mathrm{Y}_{5}$ receptor agonist mimicked the effect of NPY, inhibiting the increase in the number of TUNEL-positive cells triggered by glutamate; the percentage of apoptotic cells decreased to $68.2 \pm 6.0 \%$, compared with glutamate. This effect was completely blocked by the NPY $Y_{5}$ receptor antagonist (L-152,804). The selective NPY $Y_{1}, Y_{2}$ or $Y_{4}$ receptors agonists did not decrease the number of TUNEL-positive cells in cultures exposed to glutamate. NPY receptor agonists and antagonists alone did not increase the number of TUNEL-positive cells, compared with control (data not shown). 
A
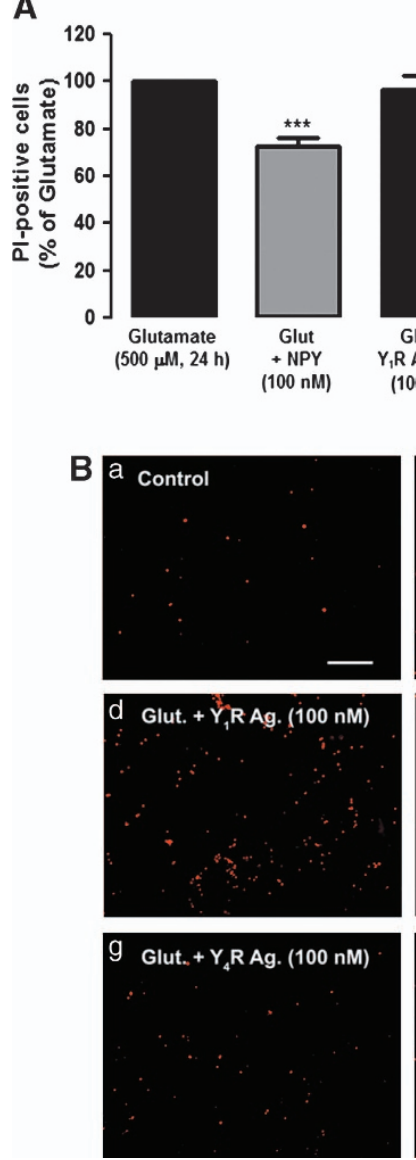
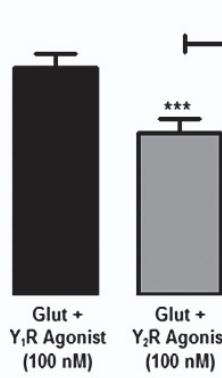

$\#$

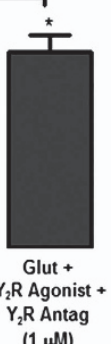

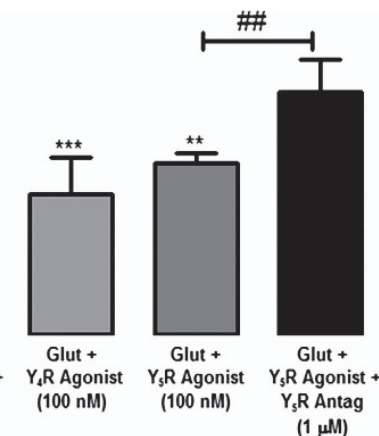
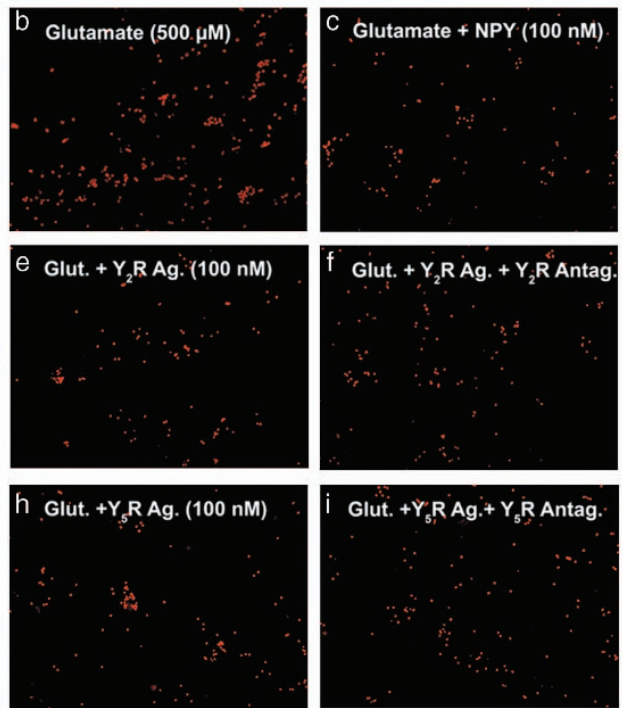

Figure 5 The activation of NPY $Y_{2}, Y_{4}$ and $Y_{5}$ receptors inhibits the necrotic cell death induced by glutamate. Necrotic cells were evaluated by PI incorporation assay. Cells were exposed to glutamate, and treated with NPY, or NPY receptor agonists and antagonists, indicated below bars. (A) Quantification of PI-positive cells (percentage of

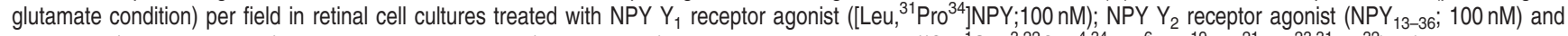

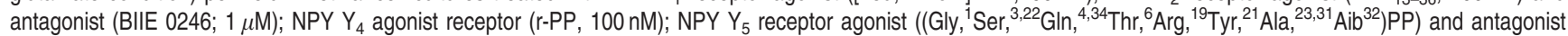
$(\mathrm{L}-152,804 ; 1 \mu \mathrm{M})$. (B) Representative images of (a) control and cultures treated with (b) glutamate, (c) glutamate $+N P Y,(d)$ glutamate $+Y_{1} R$ agonist, (e) glutamate $+Y_{2} R$ agonist, (f) glutamate $+Y_{2} R$ agonist $+Y_{2} R$ antagonist, (g) glutamate $+Y_{4} R$ agonist, (h) glutamate $+Y_{5} R$ agonist and (i) glutamate $+Y_{5} R$ agonist $+Y_{5} R$, showing PI-positive cells (red spots). Bar $=100 \mu \mathrm{m}$. Values are expressed as the percentage of PI-positive cells per field compared with the glutamate condition. The results represent mean \pm S.E.M. of $n=4-11$ independent experiments; ${ }^{\star \star \star} P<0.001$, ${ }^{\star \star} P<0.01$, compared with glutamate; ${ }^{\# \# \#} P<0.001$, ${ }^{\# \#} P<0.01$, compared with glutamate + NPY receptor agonist; one-way analysis of variance followed by Bonferroni's post-hoc test

Protein kinase A (PKA) and p38K proteins mediate the neuroprotective effect of NPY against glutamateinduced necrotic retinal neural cell death. Inhibitors of key proteins in different intracellular pathways were used to elucidate the intracellular pathways that mediate the neuroprotective effect of NPY when cells are exposed to glutamate or/and NPY (Figure 7). The PKA inhibitor, H89 $(1 \mu \mathrm{M})$, prevented the neuroprotective effect of NPY $(63.2 \pm 5.5 \%$, compared with glutamate). The number of PI-positive cells exposed to glutamate, or to glutamate plus NPY and H89, was similar. In order to confirm the involvement of PKA in the neuroprotective effect of NPY against glutamate-induced excitotoxicity, we have evaluated the effect of the PKA activator, forskolin $(10 \mu \mathrm{M})$, with cells exposed to glutamate. Forskolin decreased the number of PI-positive cells $(69.6 \pm 7.1 \%$, compared with glutamate) to a similar extent as NPY (63.2 $\pm 5.5 \%$, compared with glutamate). The protective effect of NPY against the increase of PI-positive cells triggered upon exposure to glutamate was also partially prevented ( $85.6 \pm 2.7 \%$, compared with glutamate) by the presence of the p38K inhibitor (SB203580). The inhibitors of nitric oxide synthase (NOS), protein kinase C (PKC), phosphoinositide 3-kinase (PI3K) and MEK1/2, namely L-NG-nitroarginine methyl ester (L-NAME), calphostin C, LY294002 and U0126, respectively, did not affect the neuroprotective effect of NPY against glutamate-induced toxicity (Figure 7). The inhibitors per se did not increase the number of PI-positive cells, compared with control (data not shown).

NPY protects rat retina from apoptotic cell death induced by glutamate excitotoxicity. Rat retinas were exposed to $500 \mathrm{nmol}$ glutamate for $24 \mathrm{~h}$ (Figure 8). Apoptotic cell death was assessed by TUNEL assay (Figures 8A and $\mathrm{C}$ ). The number of TUNEL-positive cells in retinal slices obtained from retinas exposed to $500 \mathrm{nmol}$ glutamate was $159.0 \pm 23.1$ cells per field. The TUNEL-positive cells were mainly located in the inner retina, especially in inner nuclear 

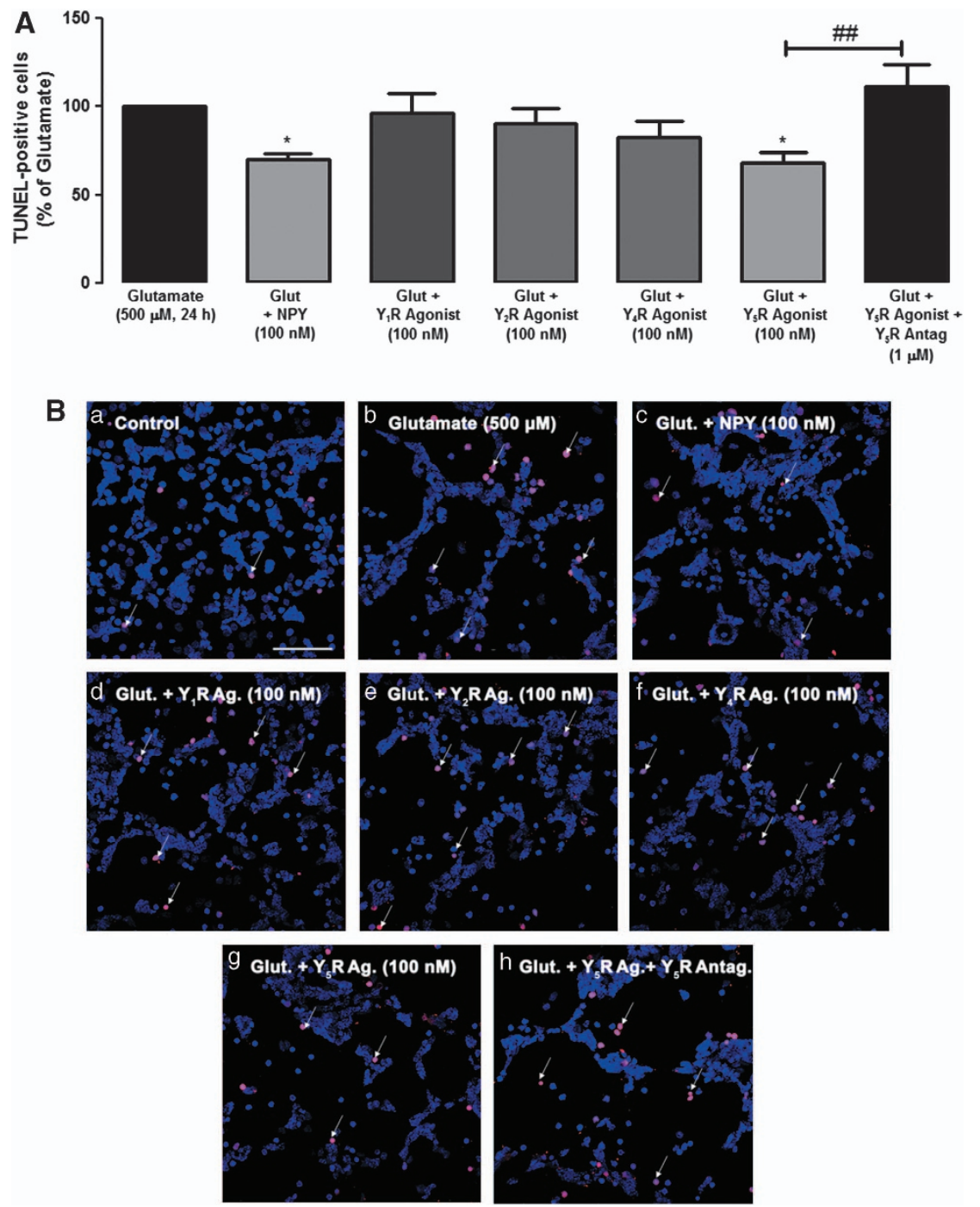

Figure 6 The activation of NPY $Y_{5}$ receptor inhibits the apoptotic cell death induced by glutamate. Apoptotic cells were assessed by TUNEL assay. Cells were exposed to glutamate and treated with NPY, or NPY receptor agonists and antagonists, as indicated below bars. (A) Quantification of TUNEL-positive cells per field compared with glutamate condition (100\%) in retinal cell cultures treated with NPY $Y_{1}$ receptor agonist ([Leu, $\left.{ }^{30} \mathrm{Pro}^{31} \mathrm{NPPY}, 100 \mathrm{nM}\right) ; \mathrm{NPY} \mathrm{Y}_{2}$ receptor agonist $\left(\mathrm{NPY} \mathrm{1}_{13-36} ; 100 \mathrm{nM}\right)$; NPY $\mathrm{Y}_{4}$ agonist receptor (r-PP, $100 \mathrm{nM})$; NPY $\mathrm{Y}_{5}$ receptor agonist ((Gly, $\left.\left.{ }^{1} \mathrm{Ser},{ }^{3,22} \mathrm{Gln},{ }^{4,31} \mathrm{Thr},{ }^{6} \mathrm{Arg},{ }^{19} \mathrm{Tyr},{ }^{21} \mathrm{Ala},{ }^{23,30} \mathrm{Aib}{ }^{32}\right) \mathrm{PP}, 100 \mathrm{nM}\right)$ and antagonist (L-152,804; $\left.1 \mu \mathrm{M}\right)$. (B) Representative images of (a) control and cultures treated with (b) glutamate, (c) glutamate $+N P Y$, (d) glutamate $+Y_{1} R$ agonist, (e) glutamate $+Y_{2} R$ agonist, (f) glutamate $+Y_{4} R$ agonist, $(g)$ glutamate $+Y_{5} R$ agonist and $(h)$ glutamate $+Y_{5} R$ agonist $+Y_{5} R$ antagonist, showing TUNEL-positive cells (purple spots - some examples are indicated by white arrows). Bar $=50 \mu \mathrm{m}$. Values are expressed as the percentage of TUNEL-positive cells per field compared with the glutamate condition. The results represent mean \pm S.E.M. of $n=5-6$ independent experiments, with ${ }^{*} P<0.05$, compared with glutamate; ${ }^{\# \#} P<0.01$, compared with glutamate $+Y_{5} R$ agonist; one-way analysis of variance followed by Bonferroni's post-hoc test

layer (INL) and ganglion cell layer (GCL). Rarely, few apoptotic cells were found in outer nuclear layer (ONL). To investigate the potential neuroprotective role of NPY against glutamate induced-toxicity, rat eyes were intravitreally injected with NPY $(2.35 \mathrm{nmol}) 2 \mathrm{~h}$ before glutamate injection $(500 \mathrm{nmol})$. When NPY was applied before glutamate, the number of TUNEL-positive cells in retinal slices decreased to $44.2 \pm 18.4 \%$ compared with glutamate, representing a $55 \%$ reduction in the number of TUNEL-positive cells.

The number of Brn3a-positive cells, a specific marker of ganglion cells in the retina, was also evaluated in the rat retinal slices (Figures $8 \mathrm{~B}$ and $\mathrm{C}$ ). Exposure of the retina to glutamate decreased the number of Brn3a-positive cells to $44.8 \pm 6.7 \%$ of control. Conversely, when NPY (2.35 nmol) was applied $2 \mathrm{~h}$ before glutamate injection in the rat vitreous, there was a protective effect as the number of Brn3a-positive cells increased (from $44.8 \pm 6.7$ to $65.7 \pm 3.1 \%$ of control).

\section{Discussion}

In this study, we investigated the protective role of NPY and NPY receptors against glutamate-induced neural cell death in rat retinal neural cells. Glutamate triggered necrosis and apoptosis in retinal cells, and NPY was able to inhibit both processes. Moreover, we have demonstrated that NPY $Y_{2}, Y_{4}$ and $Y_{5}$ receptors mediate the protective effect of NPY against necrotic cell death caused by glutamate and that NPY $Y_{5}$ receptor mediated the NPY protective effect against apoptotic 


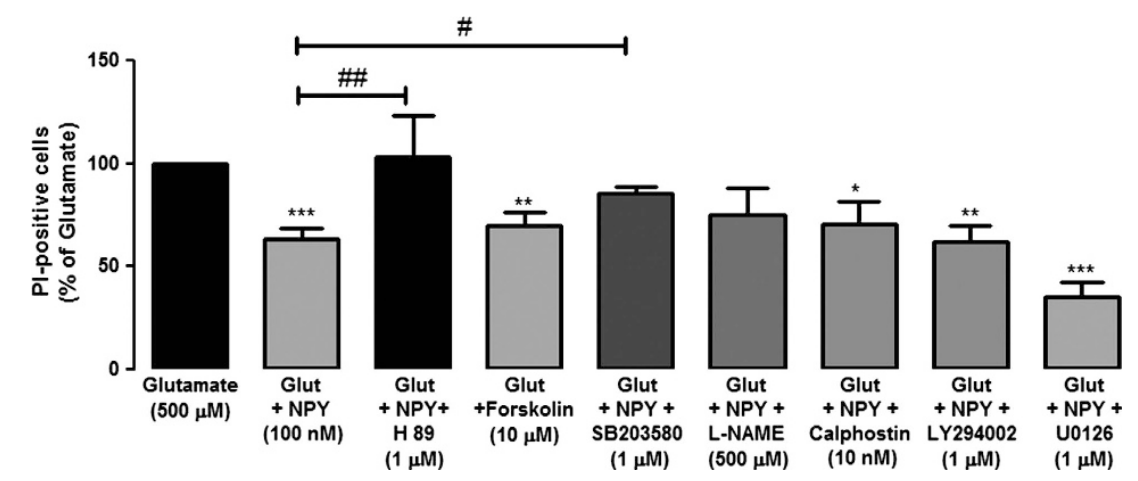

Figure 7 PKA and protein 38 kinase (p38K) mediate the neuroprotective effect of NPY against retinal neuronal cell death triggered by glutamate. The involvement of different intracellular pathways in the neuroprotective effect of NPY against glutamate-induced excitotoxicity was assessed by PI uptake (PI-positive cells), using different inhibitors of proteins involved on those pathways. Retinal cell cultures were exposed to NPY (100 nM), glutamate $(500 \mu \mathrm{M})$ and the inhibitors indicated below bars. Quantification of PI-positive cells (compared with glutamate condition) in retinal cells treated with H89 (1 $\mu \mathrm{M}$; PKA inhibitor), forskolin (10 $\mu \mathrm{M}$; PKA activator), SD203580 $(1 \mu \mathrm{M}$; p38K inhibitor), L-NAME (500 $\mu \mathrm{M}$; NOS inhibitor), calphostin C (10 nM; PKC inhibitor), LY294002 ( $1 \mu \mathrm{M}$; PI3K inhibitor) and U0126 (1 $\mu \mathrm{M}$; MEK1/2 inhibitor). Values are expressed as the percentage of PI-positive cells (per field), compared with the glutamate condition. The results represent the mean \pm S.E.M. of $n=7-9$ independent experiments, with ${ }^{* * *} P<0.001,{ }^{* *} P<0.01,{ }^{*} P<0.05$, compared with glutamate; ${ }^{\# \#} P<0.01,{ }^{\#} P<0.05$, compared with glutamate + NPY; one-way analysis of variance followed by Bonferroni's post-hoc test

A

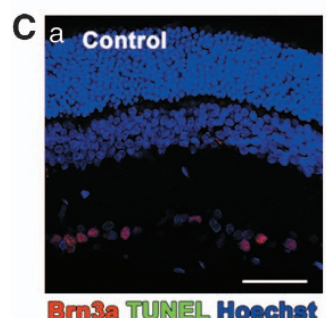

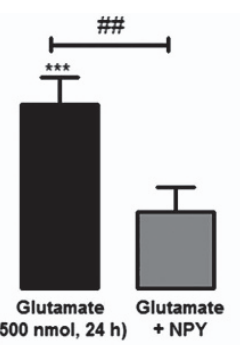

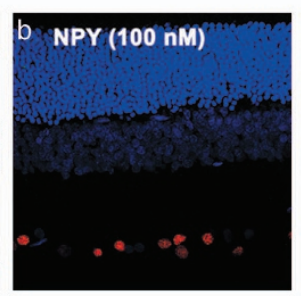

B
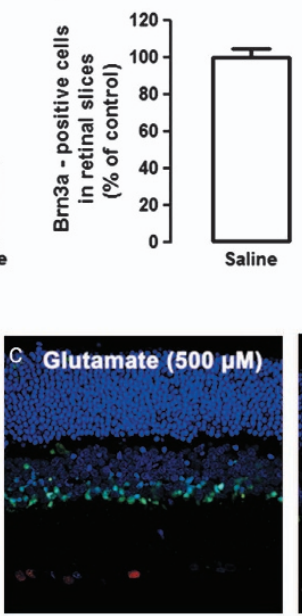
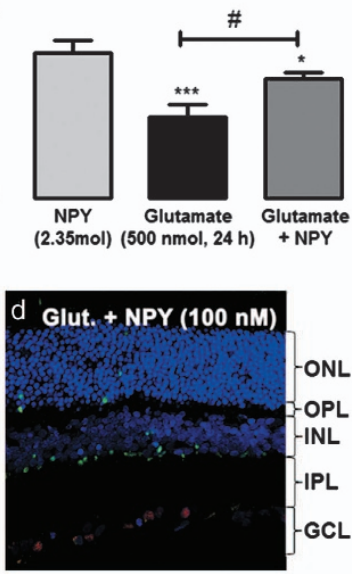

Figure 8 NPY protects against apoptotic cell death in the rat retina induced by glutamate. Cells undergoing apoptosis were identified by TUNEL assay, and ganglion cells were identified by immunohistochemistry against Brn3a (ganglion cell marker). (A) Quantification of TUNEL-positive cells in rat retinal slices (presented as percentage of glutamate condition). Retinas were exposed to glutamate $(500 \mathrm{nmol}$; intravitreal injection) and treated (or not) with NPY $(2.35 \mathrm{nmol}, 2 \mathrm{~h}$ before intravitreal injection of glutamate), as indicated below bars. Data represent the mean \pm S.E.M. of $n=3-5$ independent experiments (animals); ${ }^{* \star *} P<0.001$ compared with control; ${ }^{\#} P<0.05$, compared with glutamate; one-way analysis of variance (ANOVA) followed by Bonferroni's post-hoc test. (B) Quantification of Brn3a-positive cells in rat retinal slices (presented as percentage of control). Retinas were exposed to glutamate $(500 \mathrm{nmol}$; intravitreal injection) and treated (or not) with NPY ( $2.35 \mathrm{nmol}, 2 \mathrm{~h}$ before glutamate exposure), as indicated below bars. Data represent the mean \pm S.E.M. of $n=3-5$ independent experiments; ${ }^{* * \star} P<0.001,{ }^{*} P<0.05$, compared with control; ${ }^{\#} P<0.05$, compared with glutamate; one-way ANOVA followed by Bonferroni's post-hoc test. (C) Representative images of retinal slices obtained from eyes exposed to different conditions (intravitreal injection): (a) saline $(0.9 \% \mathrm{NaCl})$, treated with (b) NPY, (c) glutamate $(500 \mathrm{nmol})$ or (d) glutamate + NPY ( $2.35 \mathrm{nmol}, 2 \mathrm{~h}$ before glutamate), showing TUNEL-positive cells (green), Brn3a-positive cells (red), and cell nuclei stained with Hoechst 33342 (blue). NPY per se had no effect on the number of TUNEL- or Brn3apositive cells compared with control. IPL, inner plexiform layer; OPL, outer plexiform layer. Bar $=50 \mu \mathrm{m}$

cell death induced by glutamate. Additionally, we have shown that the neuroprotective effect of NPY is mediated by PKA and p38K. Finally, using an animal model, we have demonstrated that NPY also has a protective role against glutamate-induced excitotoxicity in the retina. These findings suggest that NPY can be viewed as a potential new target to protect retinal cells in retinal corresponding degenerative diseases, such as glaucoma or diabetic retinopathy.

Previous studies have shown that NPY can exert neuroprotective effects against excitotoxicity triggered by glutamate or glutamate receptor agonists in various regions of the CNS, such as hippocampus and striatum. 2,21,23,25,26 In addition, we have previously shown that NPY protects against MDMA (ecstasy) toxicity in cultured rat retinal cells. ${ }^{29}$ We extend this to show, for the first time, that NPY is able to protect necrotic and apoptotic cell death induced by glutamate in retinal cells. However, the neuroprotective effect of NPY only occurs when the peptide is applied before the excitotoxic stimulus and is not present when it is added simultaneously or after glutamate. This is consistent with the majority of studies describing a 
protective role of NPY, where the peptide was applied before the toxic stimulus. ${ }^{21,29,31}$ However, some reports have also indicated that NPY is effective when it is applied a few hours after the excitotoxic stimulus. ${ }^{23,25,32}$ Similarly, NPY was also able to protect against cell death induced by glutamate in the retina. We have shown, for the first time, that NPY exerts neuroprotective effects in the retina in vitro and using an animal model.

Glutamate excitotoxicity is characterized morphologically by a decrease in the number of neurons and a reduction in the length of neuronal processes. ${ }^{33,34}$ It induced a similar effect in rat retinal cells, which was partially prevented by NPY, specifically in neurons. In fact, NPY protected immature (TUJ1-positive cells) and mature (NeuN-positive cells) neurons in culture. Some studies indicate that Müller cells have a dual role under toxic conditions. When threatened, these cells can be either neuroprotective or contribute to exacerbate the excitotoxic stimuli (reviewed in Bringmann and Wiedemann ${ }^{35}$ ). In the present study, glutamate slightly changed the morphology of few GFAP-positive cells, increasing the thickness of their processes and decreasing the number of cell processes.

The microglial cell response to glutamate exposure was completely different. Glutamate increased the number of CD11b- and CD68/ED1-positive cells, as well as the immunoreactivity of these two markers. Glutamate and glutamate receptor agonists are known to activate microglial cells in CNS, such as the hippocampus. ${ }^{36,37}$ In the present work, both glutamate and NPY increased microglial cell proliferation, as well as microglia activation. When NPY and glutamate were present, the effect on microglia proliferation and activation was not enhanced. In contrast, other groups have reported inhibition of microglia phagocytosis and cell motility by NPY upon inflammatory challenge through the activation of NPY $Y_{1}$ receptor. ${ }^{38,39}$ In addition, NPY, via $Y_{2}$ receptors, has a protective role against methamphetamineinduced microgliosis. ${ }^{40}$ In the early stages of neurodegenerative processes, the activation of microglia contributes to neuronal protection and tissue regeneration. However, continuous retinal microglial overactivation may lead to chronic inflammation, loss of autoregulatory mechanisms, irreversible neuronal loss and photoreceptor apoptosis. ${ }^{41-44}$ Microglial activation is involved in the initiation and perpetuation of degenerative process in many diseases, such as retinal dystrophies. $^{42,45}$

Using pharmacological tools, we have shown that NPY protects retinal cells against necrotic cell death induced by glutamate through the activation of NPY $Y_{2}, Y_{4}$ and $Y_{5}$ receptors. In another study, using hippocampal slice cultures, the anti-necrotic effect of NPY was also seen to be mediated by $Y_{2}$ and $Y_{5}$ receptors. However, NPY $Y_{1}$ receptors contributed to the neuroprotective effect of NPY as well. ${ }^{21}$ Although other studies have suggested that only the NPY $Y_{1}$ or $Y_{2}$ receptors are involved in the rescue of neurons from excitotoxic cell death, ${ }^{24,25}$ the involvement of NPY $Y_{4}$ receptor has not been evaluated in majority of these.

In the present study, we show that only the NPY $\mathrm{Y}_{5}$ receptor activation protects against glutamate-induced apoptotic cell death. Another study has linked the antiapoptotic effect of NPY in the hippocampus to the activation of NPY $Y_{2}$ and $Y_{5}$ receptors. ${ }^{23}$ The difference between ours and these results might be due to the differential expression of NPY receptors in retinal and hippocampal cultures, as well as to the involvement of different signaling pathways underlying the neuroprotective effects.

We have also found that three different NPY receptors are involved in the neuroprotective effect against necrotic cell death induced by glutamate in rat retinal cell cultures. Similarly, other groups have also shown that activation of different NPY receptors can induce the same biological effect. $^{23,25,46,47}$ For example, NPY inhibits $\mathrm{KCl}$-evoked $\left[\mathrm{Ca}^{2+}\right]_{i}$ increase in retinal neurons through the activation of NPY $Y_{1}, Y_{4}$ and $Y_{5}$ receptors. There are two possible main explanations for this: (1) the formation of homo- or hetero-dimers between different NPY receptors; ${ }^{48-51}$ and (2) heterogenous distribution of these receptors through the different cell types present in the culture.

To obtain a better understanding of the intracellular mechanisms underlying the NPY neuroprotective role against necrotic cell death induced by glutamate, we have looked at the possible involvement of various pathways. The NPY protective effect may be linked to its inhibitory effect on glutamate release, as found previously in hippocampus. ${ }^{21,22}$ In rat retinal cultures, NPY inhibits both the $\left[\mathrm{Ca}^{2+}\right]_{i}$ increase induced by $\mathrm{KCl}^{46}$ and the aspartate release in these cultures (unpublished observations). NPY neuroprotection has also been associated with the involvement of ERK1/2 and Akt pathways in a Parkinson's disease model. ${ }^{26}$ In this study, we have suggested that the NPY neuroprotective role is mediated by PKA and p38K activation. The PKA inhibitor, H89, blocked the neuroprotective effect of NPY, while forskolin, a PKA activator, presented a similar protective effect to NPY, suggesting the involvement of this particular kinase in the neuroprotective effect of NPY against glutamate-induced necrotic cell death in rat retinal cells. PKA activation by NPY has been previously shown. For example, NPY has a biphasic modulatory effect on $\left[\mathrm{Ca}^{2+}\right]_{i}$ increases induced by ATP, mediates the upregulated mRNA expression of gonadotropinreleasing hormone in a neuroblastoma cell line and induces cathecolamine release in human adrenal chromaffin cells, through the activation of PKA. ${ }^{52-54}$ However, there is also evidence showing that NPY inhibits PKA. The activation of NPY receptors inhibits both the axonal transport in sensory neurons and cell proliferation in vascular smooth muscle cells, with these effects being mediated by PKA inhibition. $4,47,55-57$

We also show that NPY activates p38K, and this enzyme, as PKA, appears to mediate, at least partially, the neuroprotective role of NPY against glutamate-induced cell death. In retinal Müller cells, the activation of NPY $Y_{1}$ receptors activates p38 MAPK. ${ }^{58}$ Moreover, p38K activation protects ARPE-19 cells (retinal pigment epithelium cells) against cell death triggered by pro-oxidant conditions. ${ }^{59}$

In conclusion, NPY can have a neuroprotective role against necrotic and apoptotic cell death induced by glutamate in rat retinal cells both in cultured cells and in situ in the retina. NPY, by activating NPY $Y_{2}, Y_{4}$ and $Y_{5}$ receptors, protects retinal cells against glutamate-induced necrosis and is also able to protect against retinal cell apoptosis by activating NPY $\mathrm{Y}_{5}$ receptors. In addition, PKA and $\mathrm{p} 38 \mathrm{~K}$ mediate the neuroprotective effects of NPY. We believe these results might be 
useful to devise novel pharmacologic targets and therapies to treat retinal degenerative diseases, such as glaucoma and diabetic retinopathy.

\section{Materials and Methods}

Primary rat retinal neural cell cultures. Three-to-five-day old Wistar rat pups were used to prepare primary rat retinal cell cultures, as previously described. ${ }^{8,60}$ All procedures involving animals were in agreement with the Association for Research in Vision and Ophthalmology (ARVO) statement on vision and ophthalmic research for experimental models. Briefly, rat retinas were dissected under sterile conditions, using a light microscope, in $\mathrm{Ca}^{2+}$ - and $\mathrm{Mg}^{2+}$-free Hanks' balanced salt solution (in mM: $137 \mathrm{NaCl}, 5.4 \mathrm{KCl}, 0.45$ $\mathrm{KH}_{2} \mathrm{PO}_{4}, 0.34 \mathrm{Na}_{2} \mathrm{HPO}_{4}, 4 \mathrm{NaHCO}_{3}, 5$ glucose, $\mathrm{pH}$ 7.4) and digested with $0.1 \%$ trypsin (w/v, Gibco, Life Technologies Corporation, Paisley, UK) for $15 \mathrm{~min}$ at $37^{\circ} \mathrm{C}$. Cells were plated on glass coverslips coated with poly-D-lysine $(0.1 \mathrm{mg} / \mathrm{ml}$, Sigma-Aldrich Co. LLC, St. Louis, MO, USA) using Minimum Essential Medium Eagle (Sigma-Aldrich), supplemented with $25 \mathrm{mM}$ HEPES (Sigma-Aldrich), $26 \mathrm{mM} \mathrm{NaHCO}, 10 \%$ fetal bovine serum (Gibco) and penicillin $(100 \mathrm{U} / \mathrm{ml})$-streptomycin $\left(100 \mathrm{mg} / \mathrm{ml}\right.$, Gibco) for $8 / 9$ days $\left(37^{\circ} \mathrm{C}, 5 \% \mathrm{CO}_{2}\right)$, at a density of $2 \times 10^{6} \mathrm{cells} / \mathrm{cm}^{2}$

Animals. Adult male Wistar rats $(250-300 \mathrm{~g}$ bodyweight, Charles River, France) were housed in a temperature- and humidity-controlled environment and were provided with standard rodent diet and water ad libitum, while kept on a $12 \mathrm{~h}$ light/12 $\mathrm{h}$ dark cycle. All procedures involving the animals were in agreement to the ARVO Statement for the Use of Animals in Ophthalmic and Vision Research. Four different groups of animals were used: control (saline) injected, glutamate injected, glutamate + NPY injected, and NPY injected.

Intravitreal injections. The rats were anesthetized by isoflurane inhalation using a gas-anesthetizing system (VetEquip, Pleasanton, CA, USA). Then, oxybuprocaine $(4 \mathrm{mg} / \mathrm{ml}$; Laboratórios Edol, Linda-a-Velha, Portugal) anesthetic was applied topically to the eyes and the pupils were dilated with tropicamide (10 mg/ml; Laboratórios Edol). Using a Hamilton syringe (Hamilton, Reno, NV USA) with 33-gauge needle, $3 \mu \mathrm{l}$ of $0.78 \mathrm{mM} \mathrm{NPY} \mathrm{(total} \mathrm{amount} 2.35 \mathrm{nmol}$ ) or $3 \mu \mathrm{l}$ of $167 \mathrm{mM}$ glutamate (total amount $500 \mathrm{nmol}$ ) or sterile saline solution $(0.9 \%$ sodium chloride; Fresenius Kabi, Carnaxide, Portugal) were intravitreally injected. Control group was injected with saline solution while NPY group was injected with $2.35 \mathrm{nmol}$ NPY. Glutamate group was injected with saline and $2 \mathrm{~h}$ later with $500 \mathrm{nmol}$ glutamate. Finally, glutamate + NPY group was injected with $2.35 \mathrm{nmol}$ NPY and $2 \mathrm{~h}$ later with $500 \mathrm{nmol}$ glutamate. Fusidic acid $(10 \mathrm{mg} / \mathrm{g}$; Leo Pharmaceutical, Ballerup, Denmark) ointment was applied in the conjunctival sac at the end of the experiment. The animals were killed $24 \mathrm{~h}$ after glutamate (or saline) injection

Frozen retinal sections. Under deep anesthesia $(75 \mathrm{mg} / \mathrm{kg}$ ketamine and $10 \mathrm{mg} / \mathrm{kg}$ xylazine), rats were transcardially perfused with phosphate-buffered saline (PBS; $\mathrm{pH} 7.4$ ), followed by $4 \%$ (w/v) paraformaldehyde (PFA) in PBS. The eyes were enucleated, washed in PBS and then transferred to PFA for $1 \mathrm{~h}$. The cornea was removed and the eye cup was further fixed for $1 \mathrm{~h}$ in PFA. After washing in PBS, the eyes were cryopreserved by placing the eye cup in $15 \%(\mathrm{w} / \mathrm{v})$ sucrose in PBS for $1 \mathrm{~h}$ and then in $30 \%$ (w/v) sucrose in PBS overnight at $4{ }^{\circ} \mathrm{C}$. Finally, the eye cup was embedded in tissue-freezing medium (OCT; Sakura Finetek Europe B.V., AJ Alphen aan den Rijn, The Netherlands), the frozen blocks were cut into $10 \mu \mathrm{m}$ thickness sections in a cryostat and the cryosections were then collected on SuperFrost Plus glass slides (Menzel-Glaser, Braunschweig, Germany) and stored at $-20^{\circ} \mathrm{C}$.

Immunocytochemistry. After treatment, cells cultured on glass coverslips were washed twice with PBS and fixed in 4\% PFA (20 min; room temperature (RT)). The cells were then permeabilized with $1 \%$ Triton X-100 for $5 \mathrm{~min}$, and blocked with $3 \%$ (w/v) fatty acid-free bovine serum albumin (BSA, Sigma-Aldrich), supplemented with $0.2 \%$ Tween 20 , to prevent nonspecific binding, for $1 \mathrm{~h}$ at RT. Cells were incubated with primary antibodies for $90 \mathrm{~min}$ at RT: rabbit anti-GFAP (1:400; Dako, Glostrup, Denmark); mouse anti-GFAP protein (1:500, SigmaAldrich); rat anti-CD11b or mouse anti-CD11b (1:200; AbD Serotec, Kidlington, UK); mouse anti-TUJ1 (1:500, Covance Research Products Inc, Berkeley, CA, USA); anti-vimentin ( $1: 400$, Thermo Fisher Scientific, Waltham, MA, USA); rabbit anti-cleaved caspase $3(1: 1600$, Cell Signaling Technology, Danvers, MA, USA); mouse anti-CD68/ED1 (1:200, AbD Serotec); mouse anti-NeuN (1:400, Merck Millipore, Billerica, MA, USA). All antibody solutions were prepared in $3 \%$ fatty acid-free BSA solution.

After washing, the cells were incubated for $1 \mathrm{~h}$ at RT with secondary antibodies: Alexa 488 anti-mouse IgG, Alexa 594 anti-rat IgG or Alexa 594 anti-rabbit IgG (1: 200, Invitrogen, Life Technologies Corporation, Paisley, UK). Finally, after 5 min washing, cell nuclei were stained with Hoechst $33342(1 \mathrm{mg} / \mathrm{ml}$ in PBS, Molecular Probes, Eugene, OR, USA) for $5 \mathrm{~min}$, and, following rinsing twice with PBS, the coverslips were mounted on glass slides using Dako Fluorescent mounting medium (Dako). Cells were visualized using a fluorescence microscope (Zeiss Axioshop 2 Plus) coupled to a digital camera (Axiocam HRc) and a scanning laser confocal microscope LSM 510 META (Zeiss, Jena, Germany). Images were analyzed using Adobe Photoshop (Adobe Systems Incorporated, San Jose, CA, USA) or ImageJ (National Institutes of Health, Bethesda, MD, USA), as indicated in figure legends.

The number of cleaved caspase 3-positive cells was counted in 10-12 random fields on each coverslip, while CD11b and CD68/ED 1-positive cells were counted in 6 random fields. The number of TUJ1-, GFAP- and NeuN-positive cells was counted in 10 random z-stacks. The average number of cleaved caspase 3-, CD11b- or CD68/ED 1-, TUJ1-, GFAP- and NeuN-positive cells per random field was determined for each condition tested (control - no drug; NPY; glutamate; and glutamate $+\mathrm{NPY}$ ).

Immunoreactivity was quantified on micrographs taken after immunocytochemical experiments. Images were acquired using identical settings. The fluorescence levels (arbitrary units) were quantified using image analysis software (Image J), considering the mean grey value in six random fields per coverslip of at least three independent experiments. Negative controls were stained without primary antibodies per each immunocytochemistry performed.

Immunohistochemistry. Eye sections were fixed with acetone for $10 \mathrm{~min}$ at $-20^{\circ} \mathrm{C}$, permeabilized in PBS containing $0.25 \%$ Triton X-100 (Sigma) for $30 \mathrm{~min}$, blocked in PBS containing 10\% newborn goat serum (Gibco) and 1\% BSA for $30 \mathrm{~min}$ and incubated with a mouse anti-Brn3a (retinal ganglion cell marker; $1: 200$; Millipore) overnight at $4{ }^{\circ} \mathrm{C}$, in a closed humidified plastic container. After washing, slices were incubated with Alexa 568 anti-mouse $\lg G(1: 200$, Invitrogen) for $1 \mathrm{~h}$ at $\mathrm{RT}$.

\section{Cell viability studies}

Hoechst staining: The Hoechst33342 marker was used to label cell nuclei in rat retinal cells in culture. The Hoechst33342 fluorescence intensity was evaluated in images captured in a confocal microscope (LSM 510 Meta; Zeiss) using identical settings and image analysis software (Image J). The fluorescence intensity was obtained by the mean grey value in six random fields per coverslip of at least three independent experiments. The average of mean grey value was determined in arbitrary units in each experimental condition, and the results were expressed as a percentage of control.

PI staining: PI [3,8-Diamino-5-[3-(diethylmethylammonio)propyl]-6-phenylphenanthridinium diiodide, Sigma-Aldrich] is a polar substance that only stains the nucleus of dead or dying cells with disrupted cell membranes. In cells undergoing necrosis or late apoptosis, PI binds to DNA, emitting a bright red fluorescence $(630 \mathrm{~nm})$ when excited by blue-green light $(493 \mathrm{~nm})$. Cells plated on coverslips were exposed to 100,250 or $500 \mu \mathrm{M}$ glutamate (Sigma-Aldrich) for $24 \mathrm{~h}$ at $37^{\circ} \mathrm{C}$. In order to test for a potential protective role of NPY, cells were incubated with $100 \mathrm{nM}$ NPY (Novabiochem, Laufelfingen, Switzerland) at three different times: $1 \mathrm{~h}$ before exposure to glutamate $(500 \mu \mathrm{M})$, simultaneously with the addition of glutamate and $30 \mathrm{~min}$ after exposure to glutamate. The agonists for NPY receptors $\left(\mathrm{Y}_{1}\left(\left[\mathrm{Leu}^{31} \mathrm{Pro}^{34}\right] \mathrm{NPY}\right), \mathrm{Y}_{2}\left(\mathrm{NPY}_{13-36}\right), \mathrm{Y}_{4}\right.$ (r-PP) and $\mathrm{Y}_{5}$ ((Gly, ${ }^{1} \mathrm{Ser},{ }^{3,22} \mathrm{Gln},{ }^{4,34}$ Thr, ${ }^{6} \mathrm{Arg},{ }^{19} \mathrm{Tyr},{ }^{21} \mathrm{Ala},{ }^{23,31} \mathrm{Aib}{ }^{32}$ )PP), $100 \mathrm{nM}$, Bachem, Bubendorf, Switzerland) were also tested $1 \mathrm{~h}$ before exposure to glutamate. Cells were incubated with antagonists of NPY receptors $\left(Y_{1}\right.$ (BIBP3226); $Y_{2}$ (BIIE0246) and $Y_{5}(L-152,804)$, $1 \mu \mathrm{M}$, Tocris Bioscience, Bristol, UK) 30 min before incubation with the agonists of these receptors.

Inhibitors of key proteins in important signaling pathways were used to elucidate the signaling pathways mediating the neuroprotective effect of NPY against glutamate. The inhibitors were introduced $1 \mathrm{~h}$ before glutamate addition. $\mathrm{H} 89(1 \mu \mathrm{M}$, Tocris Bioscience was used as a PKA inhibitor. SB203580 $(1 \mu \mathrm{M})$, L-NAME $(500 \mu \mathrm{M})$, calphostin C $(10 \mathrm{nM})$, LY294002 $(1 \mu \mathrm{M})$ and $\mathrm{U} 0126(1 \mu \mathrm{M})$ were used as inhibitors of $\mathrm{p} 38 \mathrm{~K}$ inhibitor, NOS, PKC, PI3K and MEK $1 / 2$ proteins (Merck Millipore), respectively. After $24 \mathrm{~h}$ exposure to glutamate, cells were washed twice and 
incubated with PI $(7.5 \mu \mathrm{M})$ for 10 min, washed again twice and fixed with $4 \%$ PFA for $20 \mathrm{~min}$. Cells were then observed with a fluorescence microscope (Zeiss Axioshop 2 Plus) coupled to an Axiocam HRc camera. The number of PIpositive cells was counted in six random fields on each coverslip (two per condition), and the average number of $\mathrm{PI}$-positive cells per random field was determined for each condition tested.

\section{TUNEL assay}

In primary cell cultures: Cells cultured on coverslips were exposed to $500 \mu \mathrm{M}$ glutamate for $24 \mathrm{~h}$, with the drugs described above. After incubation, cells were washed twice and then incubated for $1 \mathrm{~h}$ at $37^{\circ} \mathrm{C}$ with the TUNEL mix (in situ cell death kit; Roche Applied Science, Mannheim, Germany), washed again and, finally, nuclei were stained with Hoechst 33342 for 5 min. Coverslips were mounted in Dako mounting media and images were acquired on a Zeiss PALM Microscope. The number of TUNEL-positive cells was counted in six random fields on each coverslip (two per condition), and the average number of TUNEL-positive cells per random field was determined for each condition tested.

In frozen retinal slices: After immunostaining with an anti-Brn3a antibody and the corresponding secondary antibody, TUNEL assay was performed in retinal sections according to the manufacturer's instructions (Promega, Madison, WI, USA). Nuclei were counterstained with DAPI $(1: 2000)$. The sections were coverslipped using Glycergel mounting medium (Dako) and visualized in a fluorescence microscope (Leica DM IRE2, Wetzlar, Germany). Images were acquired from the four retinal sections distanced $50 \mu \mathrm{m}$ from each other per each group. Images from six random fields were taken along each retinal section. The number of TUNEL-positive cells in the ONL, INL and GCL was counted and expressed as an average number of TUNEL-positive cells per random field from the four retinal sections. The number of Brn3a immunoreactive cell bodies was determined in images from six random fields per retinal section of a total of four retinal sections, and expressed as an average number of Brn3a-positive cells per random field from the four retinal sections.

Statistical analysis. All data are presented as mean \pm S.E.M. Statistical analysis was performed using analysis of variance followed by Bonferroni's posthoc test, as indicated in the figure legends.

\section{Conflict of Interest}

The authors declare no conflict of interest.

Acknowledgements. This work was supported by the Portuguese Foundation for Science and Technology, FEDER, and COMPETE (SFRH/BD/45311/2008, PTDC/SAU-NEU/73119/2006; PTDC/SAU-NEU/099075/2008; PTDC/NEU-OSD/ 1113/2012; PEst-/SAU/LA0001/2011; PEst-C/SAU/UI3282/2011).

1. Dumont $Y$, Martel JC, Fournier A, St-Pierre S, Quirion R. Neuropeptide $Y$ and neuropeptide $Y$ receptor subtypes in brain and peripheral tissues. Prog Neurobiol 1992; 38: 125-167.

2. Silva AP, Xapelli S, Grouzmann E, Cavadas C. The putative neuroprotective role of neuropeptide $Y$ in the central nervous system. Curr Drug Targets CNS Neurol Disord 2005; 4: $331-347$

3. Tatemoto K, Carlquist M, Mutt V. Neuropeptide Y-a novel brain peptide with structural similarities to peptide $Y Y$ and pancreatic polypeptide. Nature 1982; 296: 659-660.

4. Michel MC. Receptors for neuropeptide Y: multiple subtypes and multiple second messengers. Trends Pharmacol Sci 1991; 12: 389-394.

5. Silva AP, Cavadas C, Grouzmann E. Neuropeptide $Y$ and its receptors as potential therapeutic drug targets. Clin Chim Acta 2002; 326: 3-25.

6. Bruun A, Tornqvist K, Ehinger B. Neuropeptide Y (NPY) immunoreactive neurons in the retina of different species. Histochemistry 1986; 86: 135-140.

7. Hutsler JJ, Chalupa LM. Development of neuropeptide $Y$ immunoreactive amacrine and ganglion cells in the pre- and postnatal cat retina. J Comp Neurol 1995; 361: 152-164.

8. Alvaro AR, Rosmaninho-Salgado J, Santiago AR, Martins J, Aveleira C, Santos PF et al. NPY in rat retina is present in neurons, in endothelial cells and also in microglial and Muller cells. Neurochem Int 2007; 50: 757-763.

9. D'Angelo I, Brecha NC. Y2 receptor expression and inhibition of voltage-dependent Ca2 + influx into rod bipolar cell terminals. Neuroscience 2004; 125: 1039-1049.

10. Kishida K, Naka Kl. Amino acids and the spikes from the retinal ganglion cells. Science 1967; 156: 648-650.

11. Lucas DR, Newhouse JP. The toxic effect of sodium L-glutamate on the inner layers of the retina. AMA Arch Ophthalmol 1957; 58: 193-201.
12. Ozawa S, Kamiya H, Tsuzuki K. Glutamate receptors in the mammalian central nervous system. Prog Neurobiol 1998; 54: 581-618.

13. Gupta N, Yucel YH. Glaucoma as a neurodegenerative disease. Curr Opin Ophthalmol 2007; 18: 110-114.

14. Dkhissi O, Chanut E, Wasowicz M, Savoldelli M, Nguyen-Legros J, Minvielle F et al. Retinal TUNEL-positive cells and high glutamate levels in vitreous humor of mutant quail with a glaucoma-like disorder. Invest Ophthalmol Vis Sci 1999; 40: 990-995.

15. Martin KR, Levkovitch-Verbin H, Valenta D, Baumrind L, Pease ME, Quigley HA. Retinal glutamate transporter changes in experimental glaucoma and after optic nerve transection in the rat. Invest Ophthalmol Vis Sci 2002; 43: 2236-2243.

16. Kowluru RA, Abbas SN. Diabetes-induced mitochondrial dysfunction in the retina. Invest Ophthalmol Vis Sci 2003; 44: 5327-5334.

17. Santiago AR, Hughes JM, Kamphuis W, Schlingemann RO, Ambrosio AF. Diabetes changes ionotropic glutamate receptor subunit expression level in the human retina. Brain Res 2008; 1198: 153-159.

18. Lieth E, Barber AJ, Xu B, Dice C, Ratz MJ, Tanase D et al. Glial reactivity and impaired glutamate metabolism in short-term experimental diabetic retinopathy. Penn State Retina Research Group. Diabetes 1998; 47: 815-820.

19. Wettstein JG, Earley B, Junien JL. Central nervous system pharmacology of neuropeptide Y. Pharmacol Ther 1995; 65: 397-414.

20. Hokfelt T, Broberger C, Zhang X, Diez M, Kopp J, Xu Z et al. Neuropeptide Y: some viewpoints on a multifaceted peptide in the normal and diseased nervous system. Brain Res Brain Res Rev 1998; 26: 154-166.

21. Silva AP, Pinheiro PS, Carvalho AP, Carvalho CM, Jakobsen B, Zimmer J et al. Activation of neuropeptide $Y$ receptors is neuroprotective against excitotoxicity in organotypic hippocampal slice cultures. FASEB J 2003; 17: 1118-1120.

22. Silva AP, Xapelli S, Pinheiro PS, Ferreira R, Lourenco J, Cristovao A et al. Up-regulation of neuropeptide $Y$ levels and modulation of glutamate release through neuropeptide $Y$ receptors in the hippocampus of kainate-induced epileptic rats. $J$ Neurochem 2005; 93: $163-170$.

23. Smialowska M, Domin H, Zieba B, Kozniewska E, Michalik R, Piotrowski $P$ et al. Neuroprotective effects of neuropeptide $\mathrm{Y}-\mathrm{Y} 2$ and $\mathrm{Y} 5$ receptor agonists in vitro and in vivo. Neuropeptides 2009; 43: 235-249.

24. Xapelli S, Bernardino L, Ferreira R, Grade S, Silva AP, Salgado JR et al. Interaction between neuropeptide $Y$ (NPY) and brain-derived neurotrophic factor in NPY-mediated neuroprotection against excitotoxicity: a role for microglia. Eur J Neurosci 2008; 27: 2089-2102.

25. Xapelli S, Silva AP, Ferreira R, Malva JO. Neuropeptide $Y$ can rescue neurons from cell death following the application of an excitotoxic insult with kainate in rat organotypic hippocampal slice cultures. Peptides 2007; 28: 288-294.

26. Decressac M, Pain S, Chabeauti PY, Frangeul L, Thiriet N, Herzog H et al. Neuroprotection by neuropeptide $Y$ in cell and animal models of Parkinson's disease. Neurobiol Aging 2012; 33: $2125-2137$.

27. Croce N, Dinallo V, Ricci V, Federici G, Caltagirone C, Bernardini S et al. Neuroprotective effect of neuropeptide $\mathrm{Y}$ against beta-amyloid 25-35 toxicity in SH-SY5Y neuroblastoma cells is associated with increased neurotrophin production. Neurodegener Dis 2011; 8: 300-309.

28. Rose JB, Crews L, Rockenstein E, Adame A, Mante M, Hersh LB et al. Neuropeptide Y fragments derived from neprilysin processing are neuroprotective in a transgenic model of Alzheimer's disease. J Neurosci 2009; 29: 1115-1125.

29. Alvaro AR, Martins J, Costa AC, Fernandes E, Carvalho F, Ambrosio AF et al. Neuropeptide $Y$ protects retinal neural cells against cell death induced by ecstasy. Neuroscience 2008; 152: 97-105.

30. Streit WJ. Neuroglia. 2nd edn. Kettenmann H, Ransom BR, (eds). Oxford University Press: New York, NY, USA, 2005.

31. Thiriet N, Deng X, Solinas M, Ladenheim B, Curtis W, Goldberg SR et al. Neuropeptide $Y$ protects against methamphetamine-induced neuronal apoptosis in the mouse striatum. $J$ Neurosci 2005; 25: 5273-5279.

32. Wu YF, Li SB. Neuropeptide Y expression in mouse hippocampus and its role in neuronal excitotoxicity. Acta Pharmacol Sin 2005; 26: 63-68.

33. Mattson MP, Dou P, Kater SB. Outgrowth-regulating actions of glutamate in isolated hippocampal pyramidal neurons. J Neurosci 1988; 8: 2087-2100.

34. Doble A. The role of excitotoxicity in neurodegenerative disease: implications for therapy. Pharmacol Ther 1999; 81: 163-221.

35. Bringmann A, Wiedemann P. Muller glial cells in retinal disease. Ophthalmologica 2011; 227: $1-19$

36. Christensen RN, Ha BK, Sun F, Bresnahan JC, Beattie MS. Kainate induces rapid redistribution of the actin cytoskeleton in ameboid microglia. J Neurosci Res 2006; 84: 170-181.

37. Heppner FL, Skutella T, Hailer NP, Haas D, Nitsch R. Activated microglial cells migrate towards sites of excitotoxic neuronal injury inside organotypic hippocampal slice cultures. Eur J Neurosci 1998; 10: 3284-3290.

38. Ferreira R, Santos T, Cortes L, Cochaud S, Agasse F, Silva AP et al. Neuropeptide $Y$ inhibits interleukin-1 beta (IL-1beta)-induced microglia motility. J Neurochem 2011; 120: 93-105.

39. Ferreira R, Santos T, Viegas M, Cortes L, Bernardino L, Vieira OV et al. Neuropeptide $Y$ inhibits interleukin-1beta-induced phagocytosis by microglial cells. J Neuroinflammation 2011; 8: 169. 
40. Goncalves J, Ribeiro CF, Malva JO, Silva AP. Protective role of neuropeptide Y Y(2) receptors in cell death and microglial response following methamphetamine injury. Eur J Neurosci 2012; 36: 3173-3183.

41. Hanisch UK, Kettenmann H. Microglia: active sensor and versatile effector cells in the normal and pathologic brain. Nat Neurosci 2007; 10: 1387-1394.

42. Langmann T. Microglia activation in retinal degeneration. J Leukoc Biol 2007; 81: 1345-1351.

43. Zeiss CJ, Johnson EA. Proliferation of microglia, but not photoreceptors, in the outer nuclear layer of the rd-1 mouse. Invest Ophthalmol Vis Sci 2004; 45: 971-976.

44. Zeng HY, Zhu XA, Zhang C, Yang LP, Wu LM, Tso MO. Identification of sequential events and factors associated with microglial activation, migration, and cytotoxicity in retinal degeneration in rd mice. Invest Ophthalmol Vis Sci 2005; 46: 2992-2999.

45. Karlstetter M, Ebert S, Langmann T. Microglia in the healthy and degenerating retina: insights from novel mouse models. Immunobiology 2010; 215: 685-691.

46. Alvaro AR, Rosmaninho-Salgado J, Ambrosio AF, Cavadas C. Neuropeptide $Y$ inhibits $[\mathrm{Ca} 2+] \mathrm{i}$ changes in rat retinal neurons through NPY $\mathrm{Y} 1, \mathrm{Y} 4$, and $\mathrm{Y}_{5}$ receptors. J Neurochem 2009; 109: 1508-1515.

47. Son MY, Kim MJ, Yu K, Koo DB, Cho YS. Involvement of neuropeptide $Y$ and its $Y 1$ and $Y 5$ receptors in maintaining self-renewal and proliferation of human embryonic stem cells J Cell Mol Med 2011; 15: 152-165.

48. Dinger MC, Bader JE, Kobor AD, Kretzschmar AK, Beck-Sickinger AG. Homodimerization of neuropeptide y receptors investigated by fluorescence resonance energy transfer in living cells. J Biol Chem 2003; 278: 10562-10571.

49. Berglund MM, Schober DA, Esterman MA, Gehlert DR, Neuropeptide Y. Y4 recepto homodimers dissociate upon agonist stimulation. J Pharmacol Expe Ther2003; 307: 1120-1126.

50. Movafagh S, Hobson JP, Spiegel S, Kleinman HK, Zukowska Z. Neuropeptide Y induces migration, proliferation, and tube formation of endothelial cells bimodally via $\mathrm{Y} 1, \mathrm{Y} 2$, and $\mathrm{Y} 5$ receptors. FASEB J 2006; 20: 1924-1926.

51. Silva AP, Carvalho AP, Carvalho CM, Malva JO. Functional interaction between neuropeptide $Y$ receptors and modulation of calcium channels in the rat hippocampus. Neuropharmacology 2003; 44: 282-292.

52. Dhillon SS, Gingerich S, Belsham DD. Neuropeptide $Y$ induces gonadotropin-releasing hormone gene expression directly and through conditioned medium from mHypoE-38 NPY neurons. Regul Pept 2009; 156: 96-103.
53. Rosmaninho-Salgado J, Araujo IM, Alvaro AR, Mendes AF, Ferreira L, Grouzmann E et al. Regulation of catecholamine release and tyrosine hydroxylase in human adrenal chromaffin cells by interleukin-1beta: role of neuropeptide $Y$ and nitric oxide. J Neurochem 2009; 109: 911-922.

54. Soares Lemos V, Bucher B, Takeda K. Neuropeptide Y modulates ATP-induced increases in internal calcium via the adenylate cyclase/protein kinase A system in a human neuroblastoma cell line. Biochem J 1997; 321(Pt 2): 439-444.

55. Pons J, Kitlinska J, Jacques D, Perreault C, Nader M, Everhart L et al. Interactions of multiple signaling pathways in neuropeptide $\mathrm{Y}$-mediated bimodal vascular smooth muscle cell growth. Can J Physiol Pharmacol 2008; 86: 438-448.

56. Hiruma H, Saito A, Kusakabe T, Takenaka T, Kawakami T. Neuropeptide Y inhibits axonal transport of particles in neurites of cultured adult mouse dorsal root ganglion cells. J Physiol 2002; 543(Pt 1): 85-97.

57. Pellieux C, Sauthier T, Domenighetti A, Marsh DJ, Palmiter RD, Brunner HR et al. Neuropeptide $Y$ (NPY) potentiates phenylephrine-induced mitogen-activated protein kinase activation in primary cardiomyocytes via NPY Y 5 receptors. Proc Natl Acad Sci USA 2000; 97: 1595-1600.

58. Milenkovic I, Weick M, Wiedemann P, Reichenbach A, Bringmann A. Neuropeptide Y-evoked proliferation of retinal glial (Muller) cells. Graefes Arch Clin Exp Ophthalmol 2004; 242: 944-950.

59. Pocrnich CE, Liu H, Feng M, Peng T, Feng Q, Hutnik CM. p38 mitogen-activated protein kinase protects human retinal pigment epithelial cells exposed to oxidative stress. Can J Ophthalmol 2009; 44: 431-436.

60. Santiago AR, Pereira TS, Garrido MJ, Cristovao AJ, Santos PF, Ambrosio AF. High glucose and diabetes increase the release of [3H]-d-aspartate in retinal cell cultures and in rat retinas. Neurochem Int 2006; 48: 453-458.

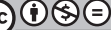

Cell Death and Disease is an open-access journal published by Nature Publishing Group. This work is licensed under a Creative Commons Attribution-NonCommercialNoDerivs 3.0 Unported License. To view a copy of this license, visit http://creativecommons.org/licenses/by-nc-nd/3.0/ 